\title{
Tectonics
}

\author{
RESEARCH ARTICLE \\ 10.1029/2018TC005386 \\ Key Points: \\ - Four 3-D sandbox models analyzing \\ the effect of synkinematic \\ sedimentation rate on fold- \\ and-thrust belts involving two \\ décollements \\ - Increasing synkinematic \\ sedimentation generates a \\ progressive change from distributed \\ deformation to localized over \\ décollement boundaries \\ - Interactions between décollements \\ strongly control the geometry, \\ kinematics, and the degree of \\ decoupling of suprasalt structures
}

Correspondence to:

O. Pla,

oriolpla@ub.edu

Citation:

Pla, O., Roca, E., Xie, H., IzquierdoLlavall, E., Muñoz, J. A., Rowan, M. G., et al. (2019). Influence of syntectonic sedimentation and décollement rheology on the geometry and evolution of orogenic wedges: Analog modeling of the Kuqa fold-and-thrust belt (NW

China). Tectonics, 38, 2727-2755.

https://doi.org/10.1029/2018TC005386

Received 29 OCT 2018

Accepted 28 JUN 2019

Accepted article online 6 JUL 2019

Published online 5 AUG 2019

(c)2019. American Geophysical Union. All Rights Reserved.

\section{Influence of Syntectonic Sedimentation and Décollement Rheology on the Geometry and Evolution of Orogenic Wedges: Analog Modeling of the Kuqa Fold-and-Thrust Belt (NW China)}

\author{
Oriol Pla ${ }^{1} \mathbb{D}$, Eduard Roca ${ }^{1}$, Huiwen Xie ${ }^{2}$, Esther Izquierdo-Llavall ${ }^{3}$ iD, Josep Anton Muñoz ${ }^{1}$ (D), \\ Mark G. Rowan ${ }^{4} \mathbb{D}$, Oriol Ferrer ${ }^{1}$, Òscar Gratacós ${ }^{1}$, Neng Yuan $^{2,5}$, and Shaoying Huang ${ }^{2}$ \\ ${ }^{1}$ Institut de Recerca Geomodels, Departament de Dinàmica de la Terra i l'Oceà, Facultat de Ciències de la Terra, \\ Universitat de Barcelona, Barcelona, Spain, ${ }^{2}$ Research Institute of Petroleum Exploration and Development, Tarim \\ Oilfield Company, PetroChina, Korla, China, ${ }^{3}$ E2S-UPPA, UPPA-CNRS-Total, Laboratoire des fluides complexes et leurs \\ réservoirs, IPRA, Université de Pau et des Pays de l'Adour, Pau, France, ${ }^{4}$ Rowan Consulting Inc., Boulder, CO, USA, \\ ${ }^{5}$ China University of Petroleum-Beijing, Karamay, China
}

Abstract Contractional deformation in the outer parts of fold-and-thrust belts is in part controlled by the presence of syntectonic sediments and multiple décollements (e.g., the Apennines, the Appalachians, the Pyrenees, the Zagros, or the Sub-Andean and Kuqa fold-and-thrust belts). To better understand the influence of these parameters in the kinematic evolution of fold-and-thrust systems, we carried out an experimental study including four 3-D sandbox models inspired by one of the previously mentioned prototypes, the Kuqa fold-and-thrust belt. This belt contains two décollements: a weak synorogenic salt layer and a deeper, preorogenic, and frictionless décollement (i.e., organic-rich shales) showing along strike variations of rheology. The experimental results show that increasing synkinematic sedimentation rate (i) generates a progressive change from distributed to localized deformation and (ii) delays the development of frontal contractional structures detached on the salt, favoring the formation and reactivation of more hinterland thrusts and backthrusts. With respect to the rheology, our study reveals that as the viscosity of the prekinematic décollement increases, (i) the deformation propagates more slowly toward the foreland, and (ii) the underlying thrust stack becomes broader and lower and has a gentler thrust taper angle. The rheology of the prekinematic décollement defines the distribution and geometry of the structures detached on it that in turn influence the development of overlying, salt-detached structures. Subsalt structures can (i) determine the areal extent of the salt and therefore of any fold-and-thrust system detached on it and (ii) hamper or even prevent the progressive foreland propagation of deformation above the salt.

\section{Introduction}

The geometry and kinematics of contractional belts are controlled by the properties of the rocks (rheology, mechanical stratigraphy, preexisting weaknesses, friction of basal, or interbedded décollements), the kinematics of convergence (obliquity and velocity), the flexural response to tectonic loading, the climatedependent surface processes (erosion, transport, and sedimentation), the fluxes within wedges (input and output), the inherited structure, and/or the changes in confining pressure and temperature (Beaumont et al., 1992; Davis et al., 1983; Fillon et al., 2013; Graveleau et al., 2012). Each one of these factors has an impact on the contractional structure and dynamics that has been widely investigated in nature and explored through analog and numerical models (Beaumont et al., 2000; Bonini, 2001; Bonnet et al., 2008; Graveleau \& Dominguez, 2008; Konstantinovskaya \& Malavieille, 2011; Ravaglia et al., 2004; Ruh et al., 2012; Simpson, 2006; Soto et al., 2002; Stockmal et al., 2007; Storti \& McClay, 1995).

It is evident from these studies that the presence of weak frictionless layers (salt or overpressured shales) results in décollements above which the contractional belt shows a lower taper angle, a wider zone of deformation, and more symmetrical structures (Jaumé \& Lillie, 1988). In these wedges, the precise external geometry and internal deformation, as well as the degree of decoupling, are determined by the strain rate, the viscosity and strength of the décollement, and the shape and depth of this weak layer (Bonini, 2003; Couzens-Schultz et al., 2003; Graveleau et al., 2012). In addition to these geometrical and mechanical factors, synkinematic erosion and sedimentation also impact the geometries because these two surface processes 
prevent the propagation of deformation toward the foreland and therefore reduce the width of the belt (Beaumont et al., 1992; Bonini, 2001; Fillon et al., 2013; Simpson, 2006; Willett, 1999). They also induce an increase of the dip and number of active thrusts (Bonnet et al., 2008; Persson et al., 2004; Storti \& McClay, 1995). Nevertheless, these general patterns are subject to variations depending on the strength profile of the deforming rocks, and when the deformed sequence includes a viscous décollement, sedimentation can either promote or inhibit foreland propagation of the deformation and the growth of a large wedge (Bonini, 2001; Smit et al., 2010).

The way in which syntectonic sedimentation interacts with the mechanical stratigraphy of the deforming rocks has been analyzed in numerous analog and numerical modeling studies. These studies have explored this interaction in fold-and-thrust systems with frictional homogeneous sequences (Bigi et al., 2010; Del Castello et al., 2004; Larroque et al., 1995; Persson et al., 2004; Persson \& Sokoutis, 2002; Storti et al., 2000; Storti \& McClay, 1995; Wu \& McClay, 2011), frictional sequences underlain by a weak basal décollement (Cobbold et al., 1993; Smit et al., 2010), and sequences incorporating a weak precontractional or syncontractional interlayered décollement (Baby et al., 1995; Bonini, 2001; Bonnet et al., 2008; Duerto \& McClay, 2009; Konstantinosvskaya et al., 2009; Leturmy et al., 2000; Massoli et al., 2006; Mugnier et al., 1997; Wang et al., 2013; Wu et al., 2014).

However, the influence of syntectonic sedimentation in fold-and-thrust systems with two décollements has rarely been tested even though it is a common scenario in the outer parts of fold-and-thrust belts such the Apennines (Scisciani \& Montefalcone, 2006), the Appalachians (Mount, 2014), the Pyrenees (Sans et al., 1996), the Zagros (Sherkati et al., 2006), or the Sub-Andean (Labaume \& Moretti, 2001) and Kuqa foldand-thrust belts (Izquierdo-Llavall et al., 2018). In all these cases, the deformational wedge includes syntectonic strata and two or more pretectonic or syntectonic décollements comprising salt, overpressured shales, or organic-rich shales. Moreover, the few published studies on this subject are essentially focused on individual structures (Darnault et al., 2016; Driehaus et al., 2014; Pichot \& Nalpas, 2009) and do not analyze sediment-décollement interaction at the regional fold-and-thrust belt scale.

In this context, the present study aims to understand how the rate of syncontractional sedimentation influences the deformation style in fold-and-thrust belts involving multiple décollements, in particular, with a décollement placed in a very weak synorogenic salt layer and a deeper, preorogenic décollement comprising a less weak organic-rich shales lithology. To achieve this, we designed an analog experimental program whose setup was inspired by the Kuqa fold-and-thrust belt (southern Tian Shan, NW China). This setup incorporated two weak layers, each with its own areal distribution that was maintained in all experiments. Moreover, the lower décollement was constructed with laterally varying strength. With these general features, four analog experiments were carried out by applying the same amount of shortening but with different synkinematic sedimentation rates.

The experimental results allowed us to develop some basic guidelines to help understand how synkinematic sedimentation affects the deformation style of fold-and-thrust belts with multiple décollements. The results compare favorably with the geometries observed across the Kuqa fold-and-thrust belt and shed light on how known sedimentation rates controlled its kinematic evolution. Besides, the models can provide a powerful tool both to help interpret the structure beneath the décollements that may be poorly imaged on seismic and to understand the kinematics and mechanics of fold-and-thrust belts which include more than one décollement and sedimentation rates that potentially changed through time. In this sense, our results should be useful not only to researchers in fold-and-thrust belt tectonics but also to industry geoscientists whose efforts are focused on hydrocarbon exploration and production in subsalt contractional environments.

\subsection{Natural Analog for the Physical Experiments: The Kuqa Fold-and-Thrust Belt}

The Kuqa fold-and-thrust belt forms the southern frontal parts of the Tian Shan intraplate chain and involves the Tarim Basin infill (Figure 1(a)). It is a south-directed thrust wedge, up to $90 \mathrm{~km}$ wide, constituted by three well-differentiated stratigraphic units (Figure 1(b)): the Paleozoic basement, formed by terrigenous, carbonated, and igneous rocks (Cai \& Lü, 2015; He et al., 2009); the Permian to Cretaceous cover which, unconformably overlying the previous unit, comprises detrital and organic-rich shales that thicken toward the north (Wang et al., 2011); and the syncontractional Cenozoic sediments that include a lower 

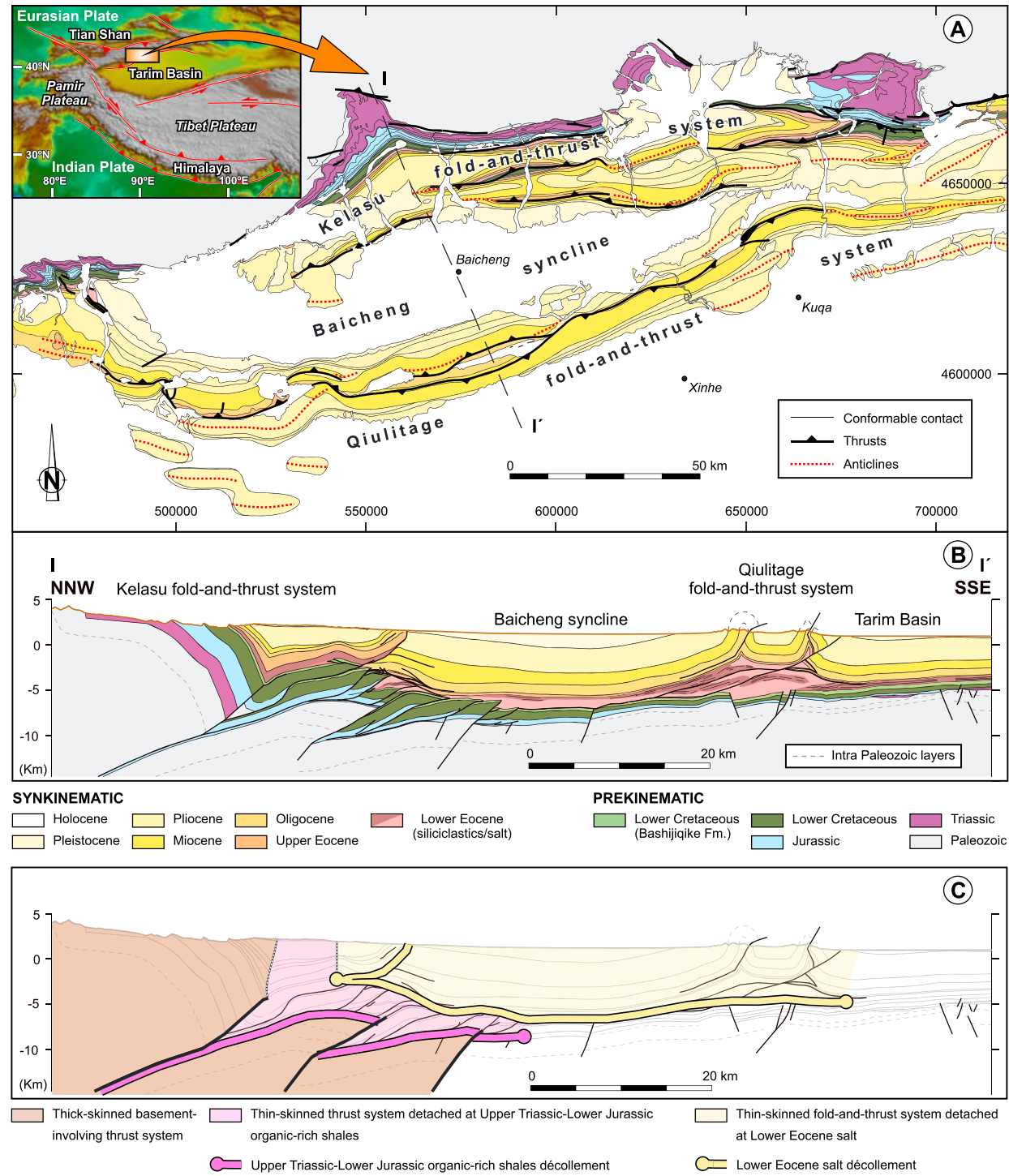

Figure 1. A location and geological map of the Kuqa fold-and-thrust belt (modified and simplified from Wang et al., 2011; UTM coordinates, zone 44 N, WGS84 datum). Black dashed line shows the location of the cross section (I-I') of b. (b) Cross-section I-I through the central fold-and-thrust belt (modified from Izquierdo-Llavall et al., 2018; see location in a). $\mathrm{C}$ same section with the location of the décollements and related pinch-outs (modified from IzquierdoLlavall et al., 2018).

Eocene salt-dominated unit overlain by thick Oligocene to Holocene terrigenous successions (Yin et al., 1998; Wang et al., 2011; Figure 1(c)).

The contractional structure of this deformed wedge is generally well constrained by surface, well, and seismic data. It consists of a broad central syncline (Baicheng syncline) bounded to the south by a narrow antiform (the Qiulitage fold-and-thrust system) and to the north by the Kelasu fold-and-thrust system (Figures 1(a) and 1(b)). The southern antiform is located above the southern pinch-out of the Eocene syncontractional salt (Figure 1(c)) and has an arcuate shape in map view (Figure 1(a)). It consists of a series of tight folds and thrust wedges detached on the salt (Chen et al., 2004; Li et al., 2012). The northern (Kelasu) fold-and-thrust system is slightly oblique to the frontal system and involves not only the syncontractional succession but also the underlying prekinematic Mesozoic and Paleozoic rocks (Figures 1(a) and 1(b)). It is mainly a south-directed thrust system involving basement structures and also two major décollements, one located in the lower Eocene salt and the other one in the Upper Triassic-Lower Jurassic organic-rich shales (Jia et al., 1998; Shuwei et al., 2010; Li et al., 2012; Ping et al., 2016; Figure 1(c)). 


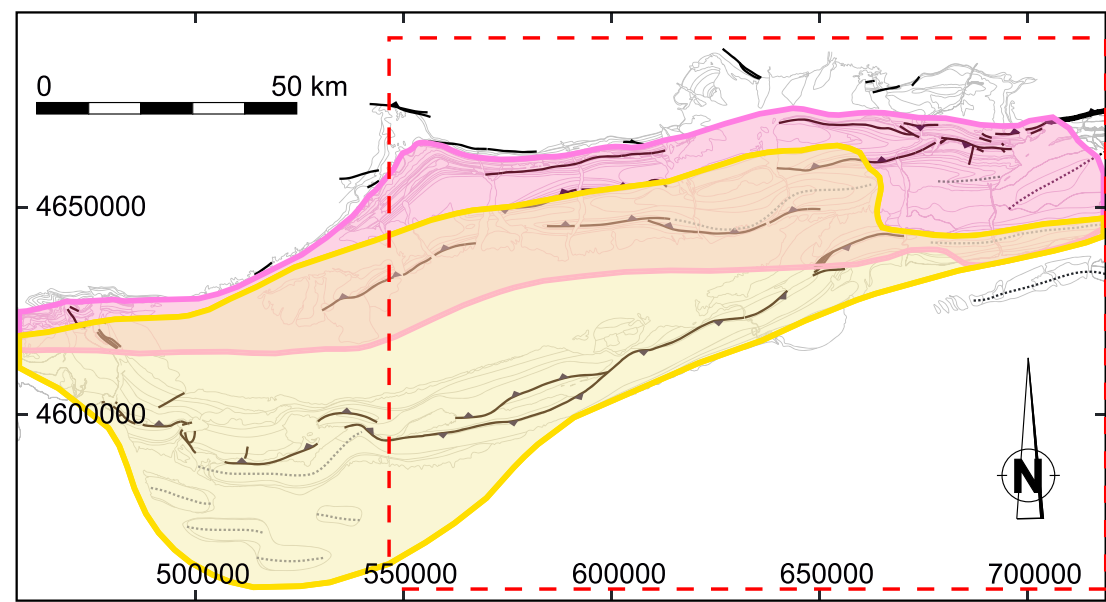

Lower Eocene décollement

Upper Triassic-Lower Jurassic décollement

Overlap between both décollements

Figure 2. Structural map of the Kuqa fold-and-thrust belt showing distribution of the lower Eocene and upper Triassiclower Jurassic décollements. The red dashed rectangle shows the area modeled in our experiments.

The two décollements have different areal distribution. The Upper Triassic-Lower Jurassic décollement is restricted to the Kelasu fold-and-thrust system and its E-W southern boundary broadly coincides with the trace of the Baicheng syncline (Figure 2). The lower Eocene salt distribution is more complex: Its southern boundary is linear toward the east but strongly arcuate farther west; its northern boundary is broadly linear except for an abrupt southward shift to the east (Figure 2) due to the expansion of laterally equivalent alluvial fans and lacustrine deltas (Liu et al., 2008). The foreland portion of the deep décollement overlaps with the hinterland portion of the salt décollement. Furthermore, whereas the mechanical behavior of the salt is apparently similar throughout its areal extent, the Upper Triassic-Lower Jurassic weak layer shows a diminution of its effectiveness as a décollement toward the west (i.e., thrusts detached along this weak layer are less abundant or absent westward; Izquierdo-Llavall et al., 2017). This is probably related to a decrease of the thickness of the organic-rich shales ( $\mathrm{Li}$ et al., 2004) and/or an increase of the percentage of coarsegrained detrital with respect to organic-rich shales and/or an increase of the maturation of the organic shales (Zhao et al., 2005).

The presence or absence of these two weak layers in the Kelasu fold-and-thrust belt has a strong impact on the structural style. Where they are absent, the Paleozoic basement and all the overlying rocks are deformed in an imbricate system of south-directed thick-skinned thrusts. Where only one exists, the Mesozoic and/or Cenozoic cover is decoupled above the thick-skinned thrust sheets with a deformation style that is strongly dependent on the rheology of the décollement. Thus, thin-skinned south-directed thrusts with hanging-wall fault-bend folds are dominant above the Upper Triassic-Lower Jurassic organic-rich shales (Jia et al., 1998; Ping et al., 2016), whereas tight detachment folds, diapirs, and thrust wedges predominate where the décollement is represented by the lower Eocene salt (Li et al., 2014; Neng et al., 2018). Finally, where both décollements overlap (Figure 1(c)), imbricate thrusts detached on the organic-rich shales form a duplex with a roof thrust along the salt (Ping et al., 2016; Shuwei et al., 2010; Xu \& Zhou, 2007). Note that the main petroleum reservoir in the Kuqa fold-and-thrust belt, the Lower Cretaceous Bashijiqike Formation (see stratigraphic column in Figure 3), is located between these two décollements.

Synkinematic sedimentation rates in the central Kuqa fold-and-thrust belt have been calculated using Cenozoic stratigraphic thicknesses (from seismic profiles; Izquierdo-Llavall et al., 2018) and magnetostratigraphic ages (Zhang et al., 2015; Zhang et al., 2016). From them, a maximum sediment-accumulation rate ranging from 0.5 to $1 \mathrm{~mm} /$ year has been estimated for the late Miocene and Pliocene to Pleistocene time spans, respectively (Izquierdo-Llavall et al., 2018). In general terms, available data indicate an increase in syntectonic sediment-accumulation rates during late Miocene (at $11 \mathrm{Ma}$ in Charreau et al., 2006; $7 \mathrm{Ma}$ in 
(A)

(B)

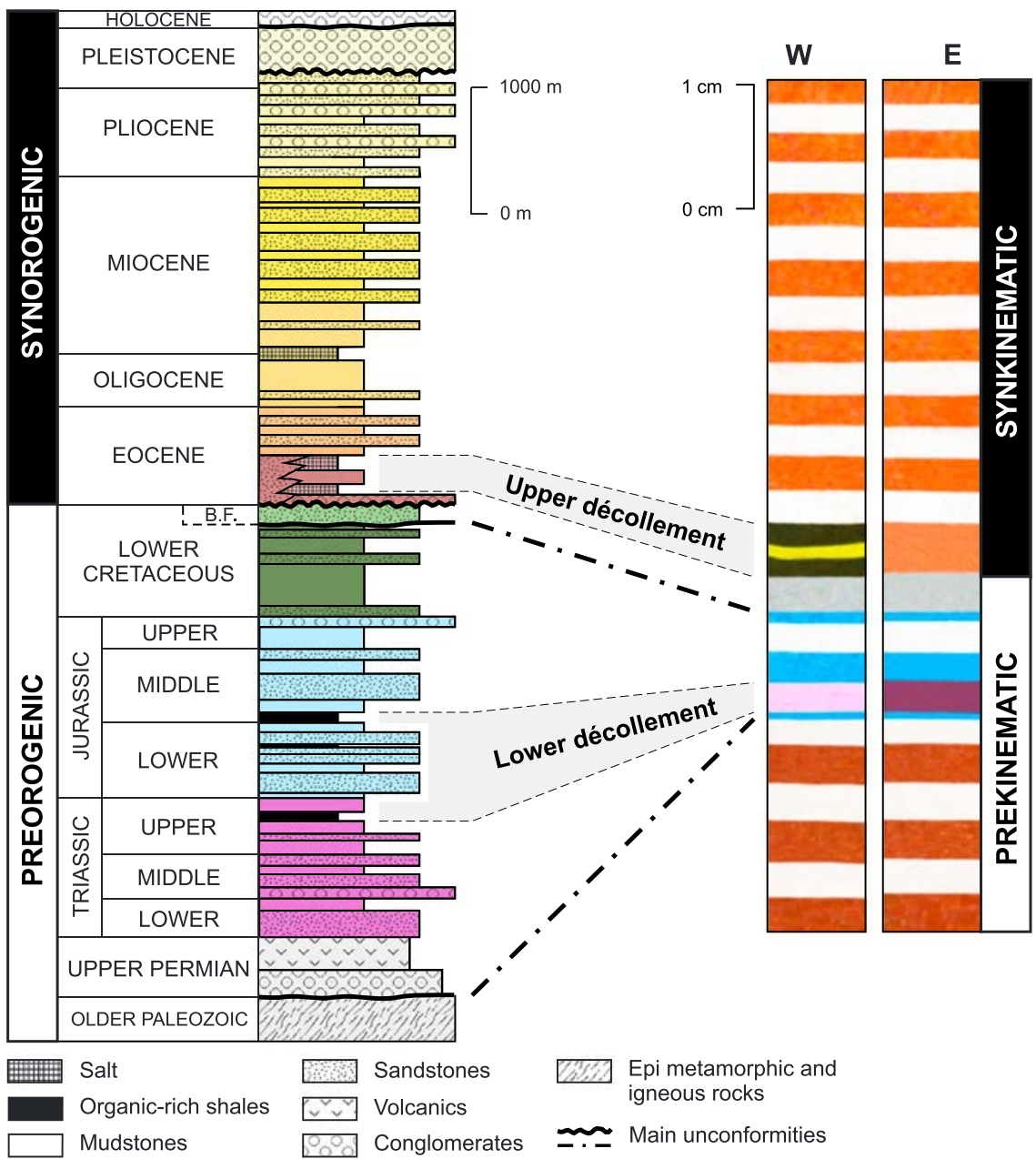

Figure 3. A stratigraphy of the Kuqa fold-and-thrust belt in the inner Kelasu fold-and-thrust system (modified from $\mathrm{Li}$ et al., 2012). B stratigraphy of the analog experiments at their central areas (equivalent to the Baicheng syncline area). See text for explanation of model décollement colors. B.F. = Bashijiqike Formation.

Huang et al., 2006) that is consistent with the increase in the shortening rate derived from sequential restorations across the central Kuqa fold-and-thrust belt (Izquierdo-Llavall et al., 2018).

\section{Experimental Methodology}

Following the methodology of analog modeling (Graveleau et al., 2012), we restricted our study to a one of the main parameters controlling the structural evolution of the frontal parts of a fold-and-thrust belt. In these scenarios, erosion is subsidiary, and fold-and-thrust development is mainly controlled by synkinematic sedimentation and lithospheric flexure (tested parameters in this experimental program; Chapman \& DeCelles, 2015; DeCelles \& Giles, 1996). Obviously, apart from the erosion, there are other influencing parameters, such as pore-fluid pressure behavior (Cobbold et al., 2001; Mourgues \& Cobbold, 2006), internal competency anisotropies, and thermal effects and their resultant changes in mechanical, that could have a strong impact in the resulting structural style. Nevertheless, they have not been addressed in this study due to the inherent limitations to scaled physical models (McClay et al., 2004).

The model setup was based on the mechanical stratigraphy observed specifically in the central part of the Kuqa fold-and-thrust belt (Figure 3). The setup was the same in all models, with the exception of the 
Table 1

Scaling Parameters Used in the Experimental Program

\begin{tabular}{|c|c|c|c|c|c|c|c|}
\hline \multicolumn{3}{|l|}{ Nature } & \multicolumn{3}{|l|}{ Experiment } & \multicolumn{2}{|c|}{ Ratio } \\
\hline Material & $\begin{array}{l}\text { Density } \\
\left(\mathrm{kg} / \mathrm{m}^{3}\right)\end{array}$ & $\begin{array}{l}\text { Viscosity } \\
\text { (pa s) }\end{array}$ & Material & $\begin{array}{l}\text { Density } \\
\left(\mathrm{kg} / \mathrm{m}^{3}\right)\end{array}$ & $\begin{array}{l}\text { Viscosity } \\
\text { (pa s) }\end{array}$ & Density & Viscosity \\
\hline Siliciclastics & $2,250-2,750^{\mathrm{a}}$ & - & Pure silica sand & 1,400 & - & $0.62-0.51$ & - \\
\hline Salt & $2,150-2,350^{\mathrm{a}}$ & $5 \times 10^{18 a}$ & Polymer (Rhodia Rhodosil GUM FM) & 970 & $0.74 \times 10^{4}$ & $0.45-0.41$ & $1.5 \times 10^{-15}$ \\
\hline $\begin{array}{l}\text { Detrital and } \\
\text { organic-rich shales }\end{array}$ & $1,400-2,250^{\mathrm{b}}$ & Unknown & $\begin{array}{l}\text { Mixture of sand and polymer } \\
(50 \% / 50 \% \text { in weight })\end{array}$ & 1,390 & $1.80 \times 10^{4}$ & $0.99-0.62$ & Unknown \\
\hline Organic-rich shales & $1,340-1,400^{\mathrm{b}}$ & Unknown & $\begin{array}{l}\text { Mixture of sand and polymer } \\
(70 \% / 30 \% \text { in weight })\end{array}$ & 1,170 & $1.05 \times 10^{4}$ & $0.87-0.84$ & Unknown \\
\hline
\end{tabular}

${ }^{\mathrm{a}}$ Values from Guo et al. (2016) ${ }^{\mathrm{b}}$ Values from Lv et al. (2016)

synkinematic sedimentation rate which varied between the four 3-D analog models. All models were carried out in a $112 \times 90 \mathrm{~cm}$ glass-sided deformation rig whose base was a fixed Mylar sheet with glued sand.

Below, we describe the materials used, the model scaling, the model setup, and the analysis methodology.

\subsection{Mechanical Properties of the Analog Materials}

We used dry silica sand, silicone/polymer, and mixtures of sand and polymer to simulate the rocks of the Kuqa contractional wedge. We used a grainy basal sheet in order to increase the basal friction of the models (coefficient of friction of 0.5-0.6; Larroque et al., 1995), leading to the growth of an imbricate thrust system of short thrust sheets with a broad cross-sectional taper, similar to that observed in the modeled area (Figure 1(b)).

Frictional materials were simulated with dry silica sand, which is nearly pure silica (99\%) and has an average grain size of $200 \mu \mathrm{m}$. This material has an angle of internal friction of about $30^{\circ}$ and a cohesion of a few tens of Pascals, being an excellent analog of brittle rocks in the upper continental crust (Krantz, 1991; Lohrmann et al., 2003; Schellart, 2000). In contrast, the two décollements were modeled using transparent polymer for salt and a mixture of pink polymer and white or black silica sand for the organic-rich shales (Figure 3 and Table 1). The pure polymer was silicone Rhodia Rhodosil GUM FM, from Bluestar Silicones (Dell'Ertole \& Schellart, 2013; Ferrer et al., 2017), a transparent or pink, high-viscosity polydimethylsiloxane polymer. Within the range of strain rates used in all experiments, it behaves as a Newtonian fluid having a very low yield strength (Dell'Ertole \& Schellart, 2013), as is the case for halite at geological time and space scales. The blend of sand and polymer was used to simulate a less effective and less mobile décollement because it reproduces a frictionless behavior but has a viscosity that is high enough to prevent its flow during the experiments. Following previous works (Callot et al., 2012; Cartwright et al., 2012; Ferrer et al., 2017), we used two mixtures with different weight proportions: 50\% white silica sand and 50\% pink polymer and $30 \%$ black silica sand and $70 \%$ pink polymer (Table 1 ).

\subsection{Scaling}

The material properties as well as the size of the models and the thickness of the deposited layers can be considered reasonably scaled compared to nature (Goncharov, 2010; Hubbert, 1937). Our model-to-nature size scaling ratios (Table 1) are similar to those used in other experiments analyzing the mechanical behavior of upper crustal rocks with interlayered weak layers (Costa \& Vendeville, 2002; Cotton \& Koyi, 2000; Ferrer et al., 2017).

In relation to the experiment kinematics and mechanics, a model-to-prototype ratio for stress $\sigma^{*}=2.7 \cdot 10^{-6}$ $6.6 \cdot 10^{-6}$ is obtained from

$$
\sigma^{*}=\rho^{*} \cdot g^{*} \cdot L^{*},
$$

where $\rho^{*}, g^{*}$, and $L^{*}$ are the scaling ratios for density, gravity acceleration, and length, respectively, with $\rho^{*}=0.41-0.99$ (Table 1 ), $\mathrm{g}^{*}=1$, and $\mathrm{L}^{*}=6.67 \cdot 10^{-6}$. The density ratio $\rho^{*}$ is the average of density ratios for the sand, the polymer, and the blend of sand and polymer that range from 0.41 to 0.99 , being slightly higher in the sand/polymer mixtures (Table 1). 


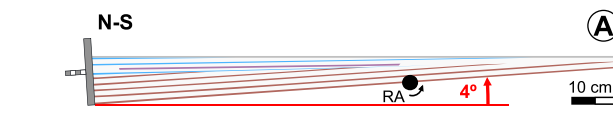

(A)
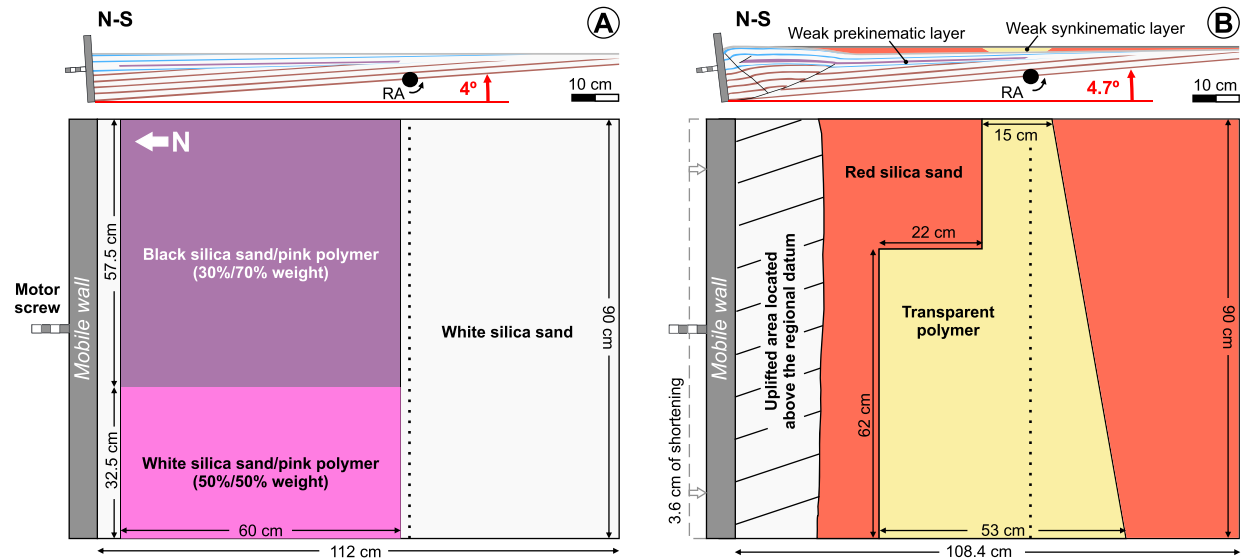

PREKINEMATIC

SYNKINEMATIC

White, brown, blue and grey pure silica sand

White silica sand/pink polymer ( $50 \% / 50 \%$ weight)

Black silica sand/pink polymer (30\%/70\% weight)
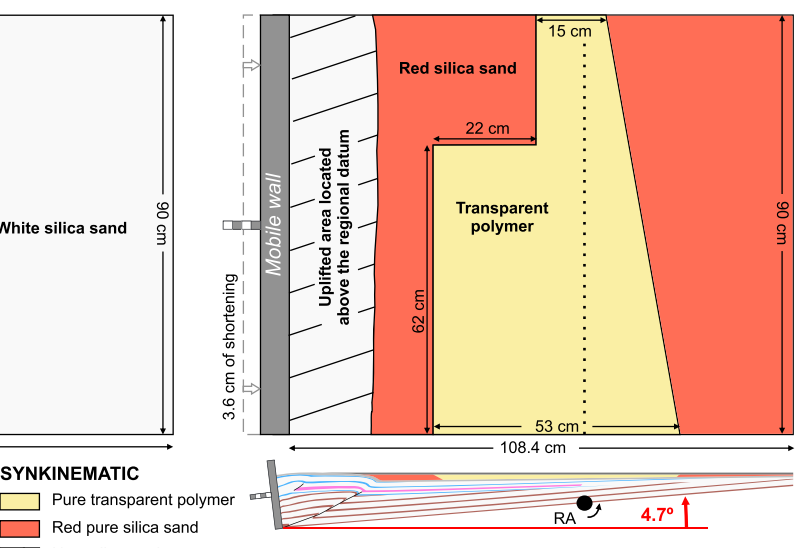

Figure 4. A lateral view of the entire prekinematic setup configuration and top view of the prekinematic weak layer configuration (organic-rich shales analog). B lateral views and top view of the experiment at the end of the deposition of the first synkinematic layer (salt analog). (RA and black dotted line) location of the baseboard rotation axis; (red arrows and texts) sense and amount of baseboard rotation.

From $\sigma^{*}$ and the viscosity ratio of the pure polymer $\eta^{*}$, the strain-rate ratio $\varepsilon^{*}$ can be calculated as

$$
\varepsilon^{*}=\sigma^{*} / \eta^{*}=2.1 \cdot 10^{9} .
$$

The time ratio $t^{*}$, which is the inverse of $\varepsilon^{*}$, is $4.76 \cdot 10^{-10}$, meaning that $1 \mathrm{hr}$ in the experiments represents about 240,000 years in nature. Our experiments lasted $45 \mathrm{hr}$, which equals $10.8 \mathrm{Myr}$ of geological time. Finally, considering the shortening-rate ratio, the scaling ratio for velocities $\mathrm{V}^{*}$ is

$$
\mathrm{V}^{*}=\mathcal{E}^{*} \cdot \mathrm{L}^{*}=13.8 \cdot 10^{3}
$$

The shortening rate in our models was $0.6 \mathrm{~cm} / \mathrm{hr}$, equivalent to $3.8 \mathrm{~mm} /$ year in nature, and the total shortening was $27 \mathrm{~cm}$ ( $40.5 \mathrm{~km}$ in nature).

\subsection{Setup and Procedure}

The deformation rig was progressively filled by a prekinematic sand wedge with three packages separated by angular unconformities (Figures 3 and 4). The lower package simulated the Paleozoic basement rocks. It consisted of a wedge with a taper angle of $2.2^{\circ}$ formed by $3-\mathrm{mm}$-thick white and brown silica sand layers (Figure 3) that were tilted $2.2^{\circ}$ toward the mobile wall and leveled by a horizontal erosive surface (Table 2 and lateral views of Figure 4).

Overlying this surface, the intermediate package mimics the gradual northward thickening of the PermianMesozoic rocks in the Kuqa belt with leveled blue and white sand layers (Figures 3 and 4 and Table 2). The exception layer, with a constant 3-mm thickness, was located in the lower part of the package and simulated the Upper Triassic-Lower Jurassic décollement (organic-rich shales) and its lateral coarser-grained detrital equivalent. They were modeled by mixed colored silica sand and polymer and white silica sand, respectively. The décollement was $60 \mathrm{~cm}$ wide and was separated by $5 \mathrm{~cm}$ from the mobile wall (Figure 4(a) and Table 2). The proportion of silica sand and polymer changed laterally from a wider, eastern portion with $70 \%$ polymer to a narrower, western portion with only 50\% polymer (Figure 4(a)). The increase of sand in the blend produces an increase in the viscosity of the analog material that tries to simulate the westward decrease in the effectiveness of the Triassic-Jurassic décollement in the Kuqa fold-and-thrust belt (see comments in section 1.1).

After the construction of the intermediate package, the models were tilted $0.6^{\circ}$ northward and leveled (Table 2), producing a low angle unconformity similar to the one observed at the base of the Lower 
Table 2

Tilting and Regional Datum Variations of Each Deposited Unit Introduced During the Setup and Posterior Experiment Running

\begin{tabular}{|c|c|c|c|c|c|c|c|}
\hline & \multirow{2}{*}{$\begin{array}{c}\text { Deposited unit } \\
\text { (number of layers) }\end{array}$} & \multirow{2}{*}{$\begin{array}{l}\text { Model tilting applied } \\
\text { before layer deposition }\end{array}$} & \multirow{2}{*}{$\begin{array}{l}\text { Accumulated } \\
\text { tilting }\end{array}$} & \multicolumn{4}{|c|}{ Regional datum variation above the axis rotation } \\
\hline & & & & Model A & Model B & Model C & Model D \\
\hline \multirow[t]{5}{*}{ Synkinematic } & Red and white sand (13) & $0.2^{\circ}$ & $7.3^{\circ}$ & 0 & $+1 \mathrm{~mm}$ & $+2 \mathrm{~mm}$ & $+3 \mathrm{~mm}$ \\
\hline & White sand layer (1) & 0 & $4.7^{\circ}$ & \multicolumn{4}{|c|}{$+3 \mathrm{~mm}$} \\
\hline & Silicone/red sand (1) & 0 & $4.7^{\circ}$ & \multicolumn{4}{|c|}{$+4 \mathrm{~mm}$} \\
\hline & Yellow sand/red sand (1) & 0 & $4.7^{\circ}$ & \multicolumn{4}{|c|}{$+1 \mathrm{~mm}$} \\
\hline & Silicone/red sand (1) & 0.7 & $4.7^{\circ}$ & \multicolumn{4}{|c|}{$+7.5 \mathrm{~mm}$} \\
\hline \multirow[t]{10}{*}{ Prekinematic } & Gray sand (1) & 0 & $4^{\circ}$ & \multicolumn{4}{|c|}{$+3 \mathrm{~mm}$} \\
\hline & \multicolumn{7}{|c|}{ Erosion } \\
\hline & & Model tilting & $0.6^{\circ}$ & & & & \\
\hline & White and blue sand (6) & $0.1^{\circ}$ & $3.4^{\circ}$ & \multicolumn{4}{|c|}{$+1.5 \mathrm{~mm}$} \\
\hline & Blue sand (1) & 0 & $2.8^{\circ}$ & \multicolumn{4}{|c|}{$+3 \mathrm{~mm}$} \\
\hline & $\begin{array}{l}\text { White sand/mixtures of sand } \\
\text { and pink polymer (1) }\end{array}$ & 0 & $2.8^{\circ}$ & \multicolumn{4}{|c|}{$+3 \mathrm{~mm}$} \\
\hline & Blue and white sand (3) & $0.2^{\circ}$ & $2.8^{\circ}$ & \multicolumn{4}{|c|}{$+0.5 \mathrm{~mm}$} \\
\hline & \multicolumn{7}{|c|}{ Erosion } \\
\hline & & Model tilting & $2.2^{\circ}$ & & & & \\
\hline & Brown and white sand (19) & 0 & 0 & \multicolumn{4}{|c|}{$+3 \mathrm{~mm}$} \\
\hline
\end{tabular}

Cretaceous Bashijiqike Formation in the Kuqa fold-and-thrust belt (Figures 1 and 3). This was covered by a constant thickness ( $3 \mathrm{~mm}$ thick) layer of pure gray sand representing the uppermost prekinematic package (Bashijiqike Formation).

Once the prekinematic wedge was built, the four models were shortened by pushing the northern wall of the rig with a motor-driven worm screw (Figure 4). The wall moved to the south a total of $270 \mathrm{~mm}$ at a constant velocity of $6 \mathrm{~mm} / \mathrm{hr}$. A progressive tilting of the basal plate toward the pushing wall (Figure 4) accompanied shortening in order to reproduce the foreland flexure due to the piling of basement thrust sheets in the hinterland (the Tian Shan in our case). The tilting values and rates were estimated according to the Kuqa foldand-thrust belt where the autochthonous basement flexed toward the hinterland about $2.5-4.5^{\circ}$ during the fold-and-thrust development (Figure 1; Izquierdo-Llavall et al., 2018). This flexure was simulated in our experiments with a total syncontractional tilting of $3.3^{\circ}$ (see accumulated tilting values in Table 2 ), which entailed a tilting rate of $0.2^{\circ}$ for each $18 \mathrm{~mm}$ of shortening.

Shortening and coeval tilting were accompanied by the deposition of synkinematic layers. The first synkinematic layer, simulating the lower Eocene salt and detrital lateral equivalents, was added after $3.6 \mathrm{~cm}$ of shortening, when the model topography and equivalent shortening were similar to those inferred at the time the salt was deposited in Kuqa (Izquierdo-Llavall et al., 2018). Salt and its detrital equivalents were modeled by transparent polymer and red silica sand, respectively. The polymer distribution was polygonal to mimic the areal extent of the salt in the Kuqa Basin (Figures 4(b) and 5), with the sand around it representing the laterally equivalent siliciclastic rocks. The polymer body included an interbedded 1-mm-thick yellow silica sand layer, located $0.4 \mathrm{~cm}$ beneath the top, to reproduce the real stratigraphy of the Kuqa evaporite sequence (Figure 3). Once the surface of the polymer was totally horizontal, it was covered by a 3-mm-thick layer of white sand (Figure 3 and Table 2).

In Model A, no more sand was added after this white sand layer just above the pure polymer. In the other three models, this layer was totally or partially covered by 13 layers of red and white silica sand whose thickness varied in the different models. They were added after each $1.8 \mathrm{~cm}$ of shortening $\left(0.2^{\circ}\right.$ tilting $)$ until the end of the experiment. These layers simulated continuous synkinematic deposition and where progressively added rising the prekinematic regional datum above the axis rotation of the experimental apparatus (Figure 4). Depending on the experiment (Models A-C, Table 2), each synkinematic layer was gradually raised 1, 2, or $3 \mathrm{~mm}$, respectively, above the axis rotation of the rig (Figure 4). Finally, the models were covered by postkinematic dry sand, preserved, and sliced into closely spaced vertical serial sections (3 mm thick). 


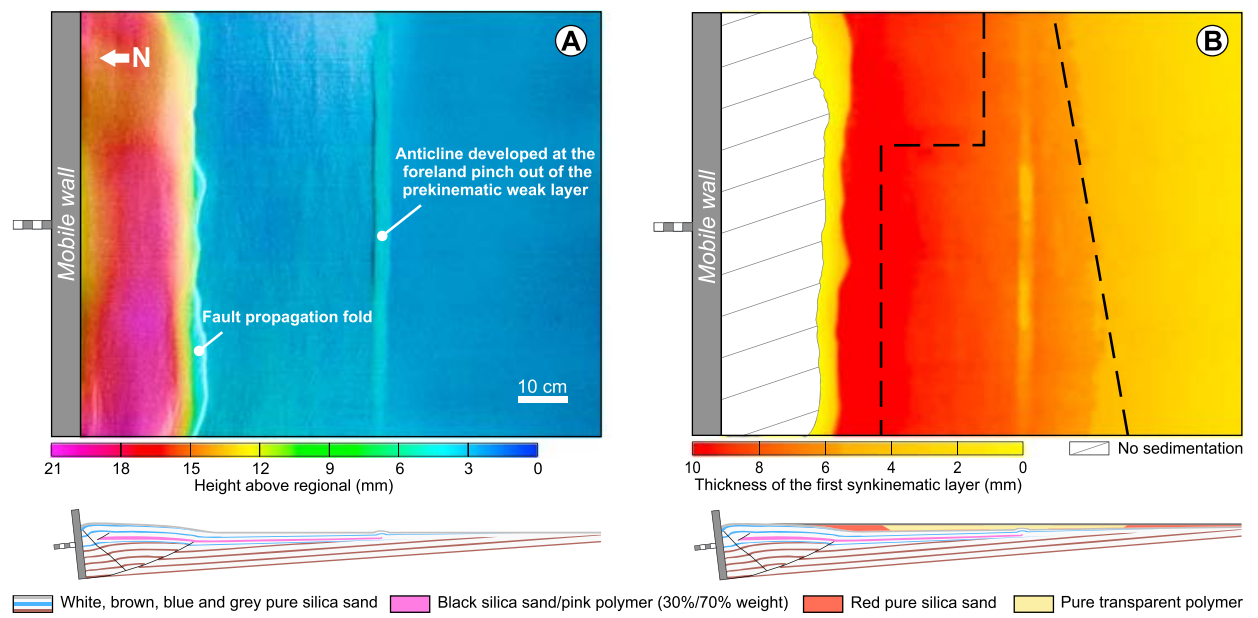

Figure 5. A topography of experiment B (obtained by laser scan) before addition of the first synkinematic layer and the western lateral view. B Isopach map of the first synkinematic layer with the boundaries of the pure polymer body (black dashed lines) and the western lateral view.

\subsection{Model Analysis Procedure}

The evolution of the experiments was documented and subsequently analyzed by means of lateral, oblique, and overhead time-lapse photographs taken every $2 \mathrm{~min}$. In addition, scans of the model topography using a submillimeter resolution white light scanner (SidioPro from Nub3D) were performed after construction of the prekinematic wedge and subsequently after every $1.8 \mathrm{~cm}$ of shortening, prior and after deposition of each synkinematic layer.

In order to reconstruct and analyze the final structure of the model, the vertical sections cut at the end of each experiment were also photographed using high-resolution digital cameras. These photographs were used to reconstruct 3-D virtual volumes of the experiments and the generation of key horizons (i.e., base and top of the weak layers) with Move 2015.2 software from Midland Valley.

\section{Experimental Results}

In all four experiments, the contractional deformation was similar up to deposition of the first synkinematic layer after $3.6 \mathrm{~cm}$ of shortening. After an initial horizontal porosity reduction of the sand by layer-parallel shortening, the prekinematic package was deformed by one or two $23-26^{\circ}$ dipping forethrusts pinned at the base of the mobile wall and subsequently by a steeper minor backthrust that branched off the lower forethrust (upper lateral view of Figure 4(b)). During displacement of the deep thrusts, the overburden of the prekinematic weak layer was deformed by fault-propagation folds above the thrust pin lines and smaller forethrusts and detachment anticlines at the hinterland and foreland weak layer pinch-outs (Figures 4 and 5).

During this stage, the lateral changes in the mechanical stratigraphy (composition) of the weak layer did not appear to affect significantly the deformation. The structures were consistent along the length of the experiments, except that the height of the anticline formed at the foreland pinch-out was slightly lower above the sand/polymer mixture with a larger proportion of sand (western part of the experiments; Figure 5(a)).

The initial contractional wedge structure was partially covered by the first synkinematic layer (Figure 5(b)). Afterward, in all four experiments, ongoing shortening resulted in the growth of a contractional wedge with an inner, thick-skinned domain where the entire package thickened by thrusts detached on the experiment baseboard and an outer, thin-skinned domain in which the contractional deformation was restricted to a fold-and-thrust system detached on the polymer layers (Figures 6-8). Thus, they generated a structural zonation similar to that observed in any orogen with cover décollements (Zagros, southern Canadian Rockies, Pyrenees, eastern Alps, and of course the Kuqa Basin), in which there is a hinterland stack of basementinvolved thrusts and a foreland system of folds and thrusts detached on synkinematic or prekinematic 

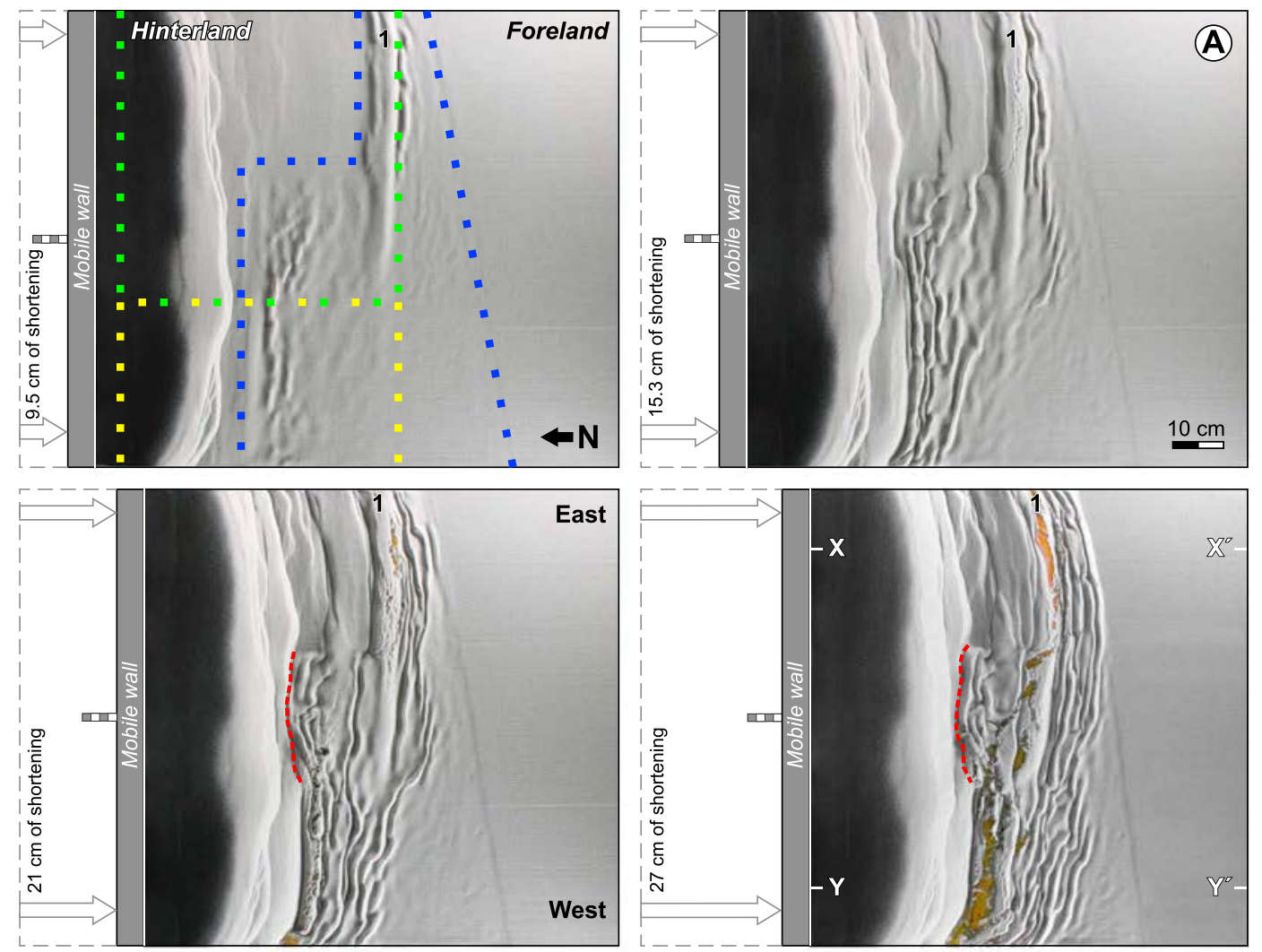

" - " - Prekinematic sandy polymer ( $30 \%$ sand $/ 70 \%$ polymer in mass) pinch-outs

- - Synkinematic polymer pinch-outs

1. 1 - Prekinematic sandy polymer ( $50 \%$ sand $/ 50 \%$ polymer in mass) pinch-outs

---- Active thin-skinned backthrusts

$X$ - X' (East)

Hinterland Prekinematic sandy polymer pinch-out

Outer thin-skinned domain

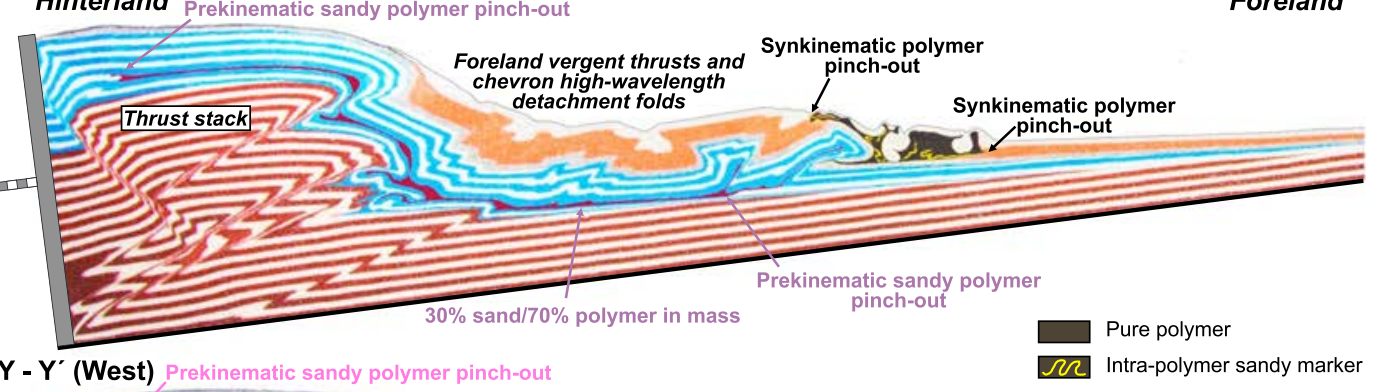

(B)

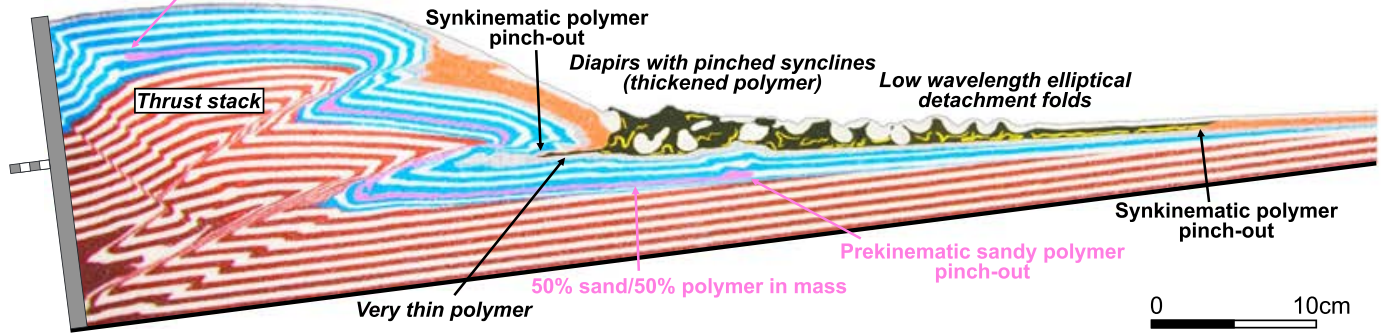

Figure 6. A sequential top views of experiment a showing the locations of the boundaries of both décollements and the active thin-skinned thrusts and folds. B cross sections of experiment a at the end of compression (27-cm shortening), see locations in the equivalent top view in a.

décollements over undeformed basement (Bally et al., 1966; Lammerer et al., 2008; Molinaro et al., 2005; Muñoz, 1992; Vergés et al., 2011; Wang et al., 2011). Having said that, the geometry and kinematics of the inner and outer domains were not equal in the four experiments, which showed some significant differences that are outlined below. 

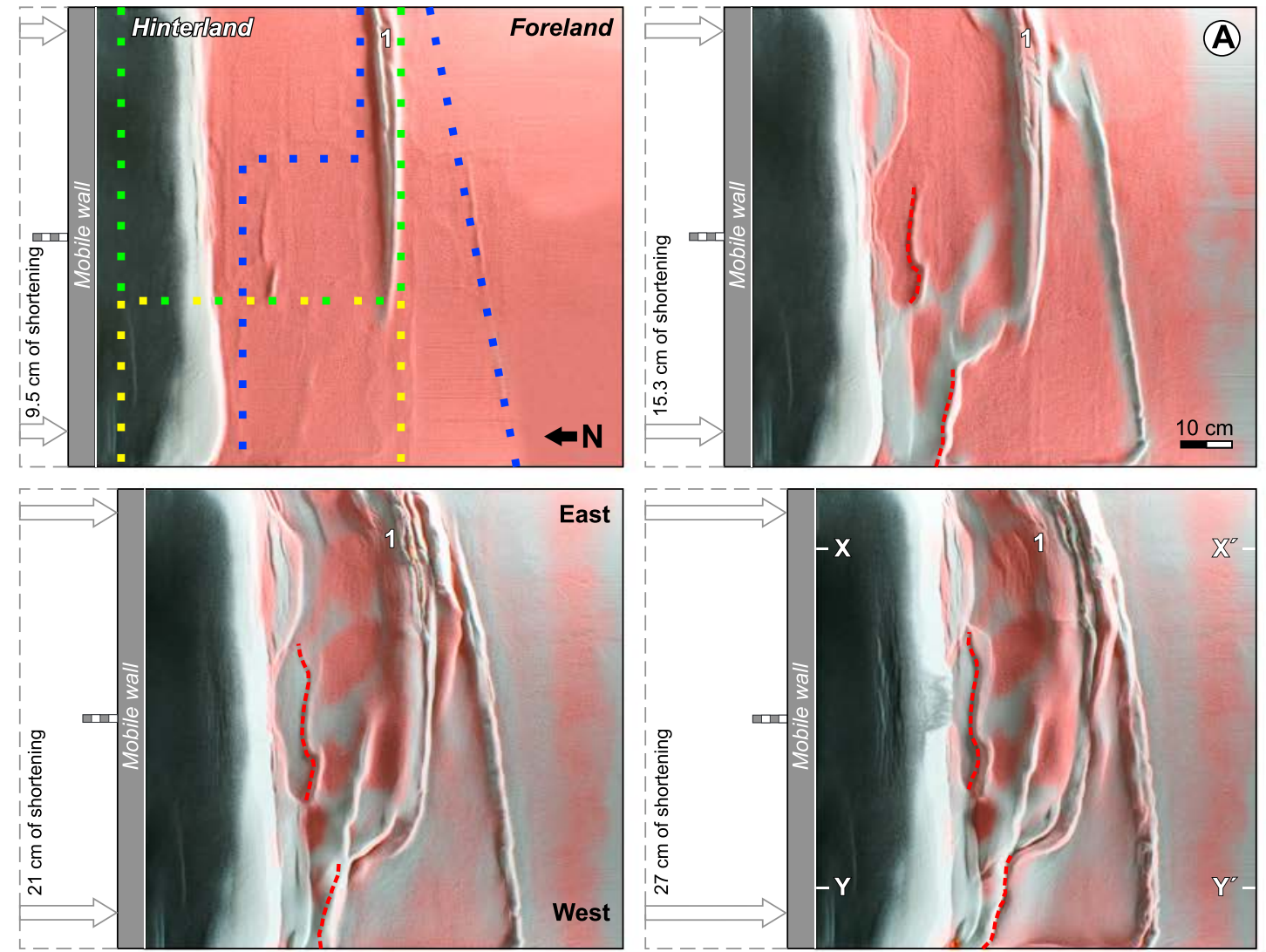

- " - " Prekinematic sandy polymer ( $30 \%$ sand $/ 70 \%$ polymer in mass) pinch-outs

1 $=$ - Prekinematic sandy polymer $(50 \%$ sand $/ 50 \%$ polymer in mass) pinch-outs

- - Synkinematic polymer pinch-outs

----- Active thin-skinned backthrusts

$X$ - $X^{\prime}$ (East)

Inner thick-skinned domain

Outer thin-skinned domain

(B)

Hinterland

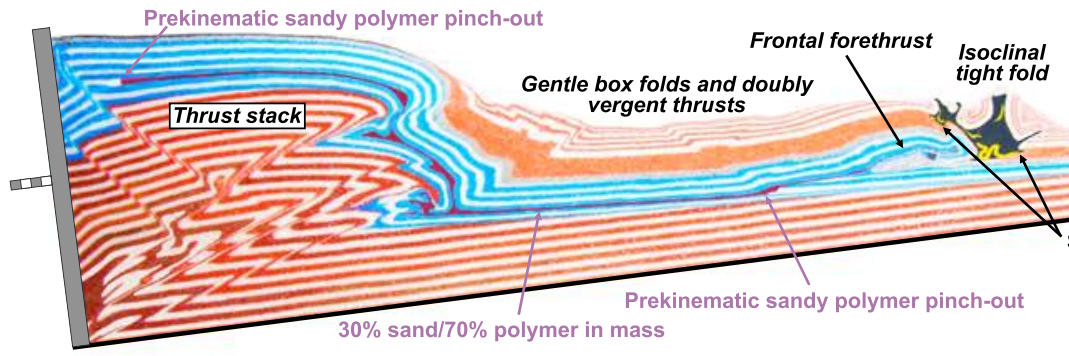

Y $-Y^{\prime}$ (West)

$0 \%$ sand $/ 70 \%$ polymer in mass

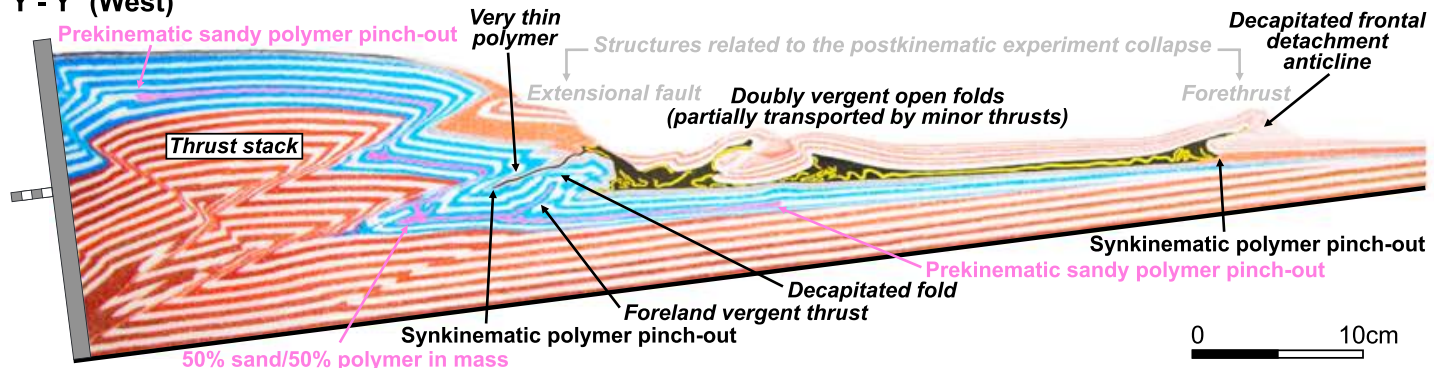

ynkinematic polymer pinch-outs

$\square$ Pure polymer

Intra-polymer sandy marker

Foreland 

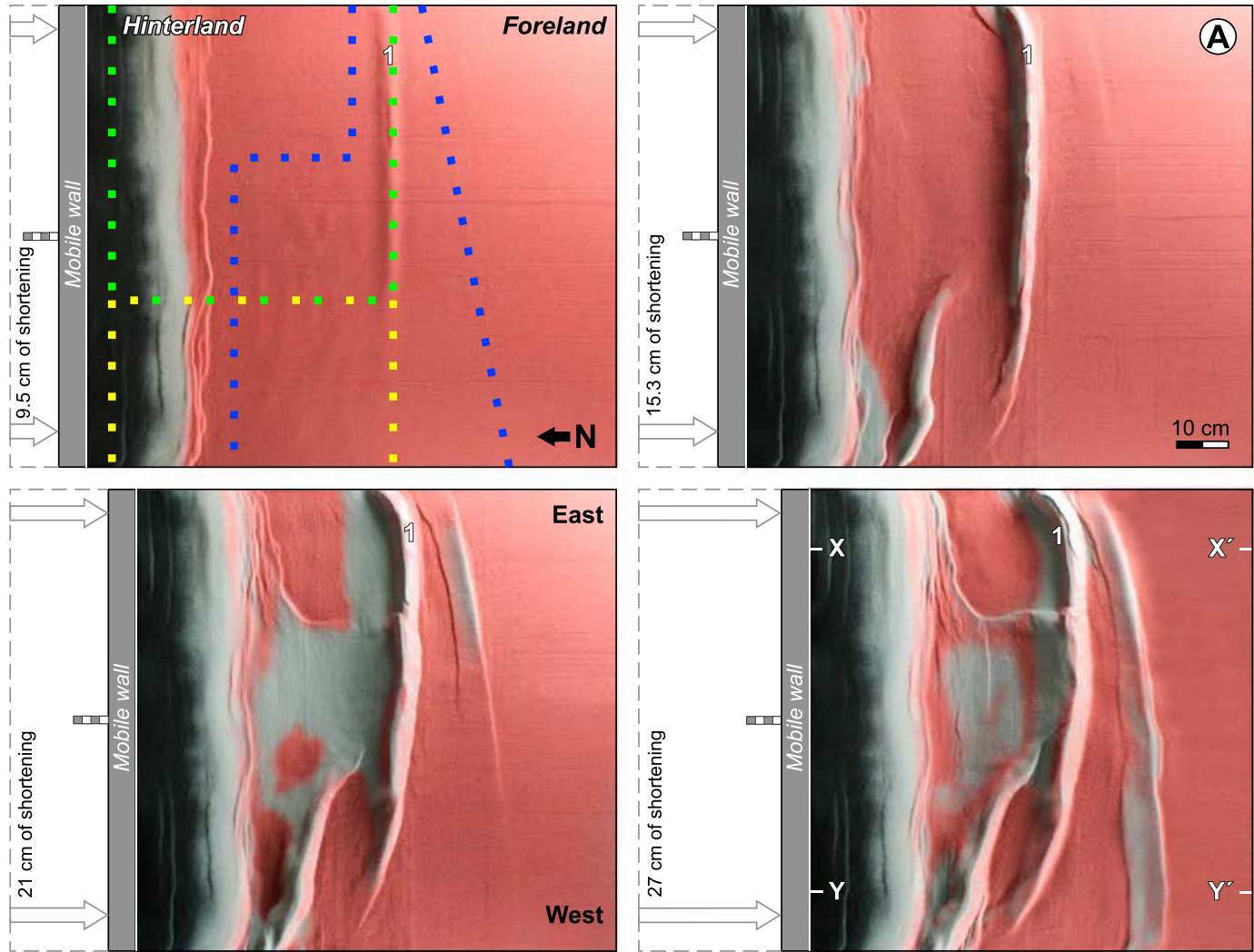

1- . Prekinematic sandy polymer ( $30 \%$ sand $/ 70 \%$ polymer in mass) pinch-outs

- - Synkinematic polymer pinch-outs

a - Prekinematic sandy polymer ( $50 \%$ sand $/ 50 \%$ polymer in mass) pinch-outs

$X$ - $X^{\prime}$ (East) Inner thick-skinned domain

Outer thin-skinned domain

(B)

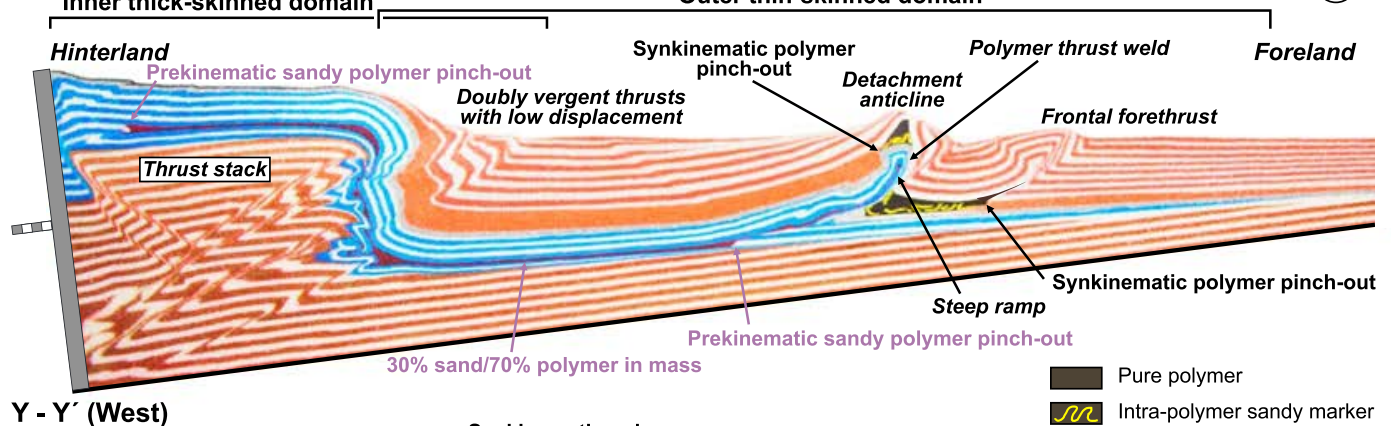

Y = Y' (West)

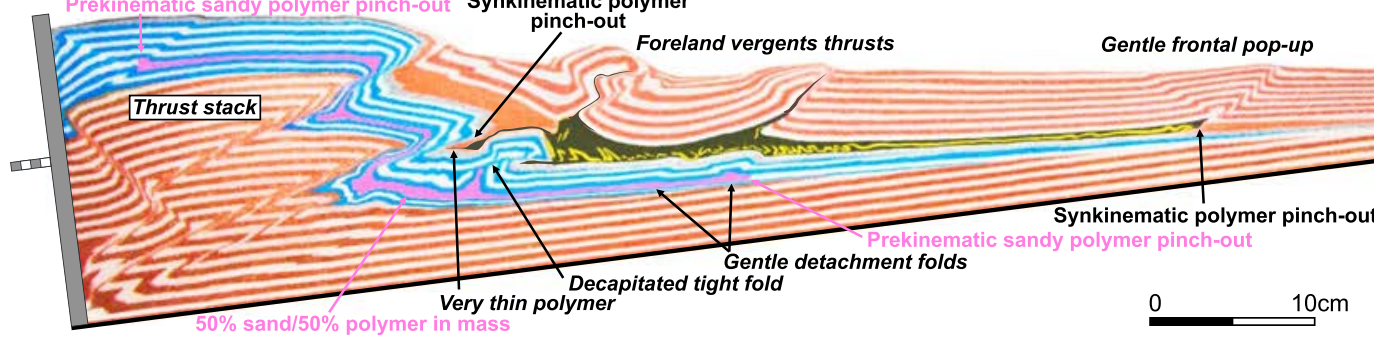

Figure 8. A sequential top views of experiment D showing the locations of the boundaries of both décollements and the active thin-skinned thrusts and folds. B cross sections of experiment $\mathrm{D}$ at the end of compression (27- $\mathrm{cm}$ shortening), see locations in the equivalent top view in a. 


\subsection{Experiment Without Additional Synkinematic Sedimentation (Experiment a)}

\subsubsection{Inner Thick-Skinned Domain}

The inner thick-skinned wedge formed by the stacking of several thrusts dipping $14-26^{\circ}$ toward the hinterland. They were detached on the baseboard of the experimental apparatus. Where the prekinematic layer was weaker (east), a duplex formed with a roof in the weak layer; in contrast, where this layer was a less effective décollement (west), the thrusts cut the prekinematic weak layer (Figure 6(b)).

The lateral change in weak-layer viscosity and effectiveness also influenced the number and maximum displacements of the thrusts. In particular, more thrusts with smaller individual displacement developed where the prekinematic weak layer had a higher polymer proportion and was thus more effective as a décollement (Figures 6 and 9). Correspondingly, the inner-domain taper was broader, lower, and gentler where the prekinematic layer was stronger: Taking the top of the prekinematic package as reference level, the forelimb of the thrust stack dipped $32^{\circ}$ in this area but $40^{\circ}$ where the layer was weaker (Figure 6(b)).

The deformation kinematics of the inner domain was characterized by late-stage development of backthrusts branching off the forethrusts. These backthrusts cut and shifted the overlying thrusts (Figure 6(b)), thereby indicating wedge growth by emplacement of the forethrusts in a piggy-back (foreland-propagating) sequence.

\subsubsection{Outer Thin-Skinned Domain}

A fold-and-thrust system developed detached at the prekinematic sand/polymer mixture and/or the synkinematic pure polymer layer. The structure and kinematics of this thinner contractional wedge was controlled by (1) the areal distribution of the weak layers and (2) the lateral change in efficiency of the deeper layer (Figure 6(a)). Only the areas in which the prekinematic weak layer had a higher polymer proportion did it continue to act as an effective décollement. Thus, the prekinematic sediments of the outer thin-skinned domain were only involved in the deformation in the eastern part of the thin-skinned fold-and-thrust system (Figure 6, Section $\mathrm{X}-\mathrm{X}^{\prime}$ ); to the west, shortening was detached at the higher, synkinematic weak layer (Figure 6, Section $\mathrm{Y}_{-} \mathrm{Y}^{\prime}$ ). As a result, the style and kinematics of the contractional deformation above these two décollements was significantly different in each region.

To the east, where the prekinematic décollement was more effective (i.e., less viscous), box folds and forethrusts detached on this layer. Box folds initially grew at or near the foreland pinch-out of the weak layer (Figure 6(a)); as shortening progressed, they were cut and transported by forethrusts emanating from their cores. Motion on these thrusts was accompanied by the formation of thrusts and folds that grew in a breakback sequence. Deformation of the prekinematic sandy polymer and its overburden always took place in front of the toe of the active thick-skinned thrust system. From the observation of sequential photographs, hindward thin-skinned structures became inactive as they were tilted/uplifted by the foreland-propagating thick-skinned thrusts, and no deformation was transferred to the hinterland pinch-out of the prekinematic weak layer (Figure 6(b)).

Shortening developed over the synkinematic weak layer had a completely different style and was decoupled from any deeper structures. The synkinematic overburden formed symmetric upright detachment folds with smaller amplitude and wavelength than those above the prekinematic weak layer. Most of these evolved through time into pinched synclines between diapirs where the polymer broke through anticline hinges (Figure 6(b), Section $\mathrm{Y}^{-\mathrm{Y}^{\prime}}$ ). The amount of extruded polymer was controlled by the initial thickness of the source layer which, being thicker toward the hinterland, resulted in encasement of the pinched synclines.

Shortening above the synkinematic décollement started near its hinterland pinch-out and propagated toward the foreland. To the west, where the prekinematic layer was stronger, the frontal thick-skinned thrust merged upward with the hindward edge of the shallow décollement; to the east, however, it was the frontal thin-skinned thrust developed above the deeper weak level that merged upward with the shallow décollement (Figure 6(b)). In the latter case, the frontal structure detached at the deep level folded the hindward portion of the shallow polymer layer, above which a backthrust developed at the hindward pinch-out (Figure 6(b), Section X-X'). Eventually, the deformation front reached the foreland pinch-out of the shallow polymer, after which the contractional front remained fixed.

The deformation front above the pure polymer layer was shifted gradually but significantly over the boundary between the two sand/polymer mixtures. As shortening increased and deformation stacked at the foreland pinch-out of the shallow décollement in the east, the lateral shift progressively diminished until it was 

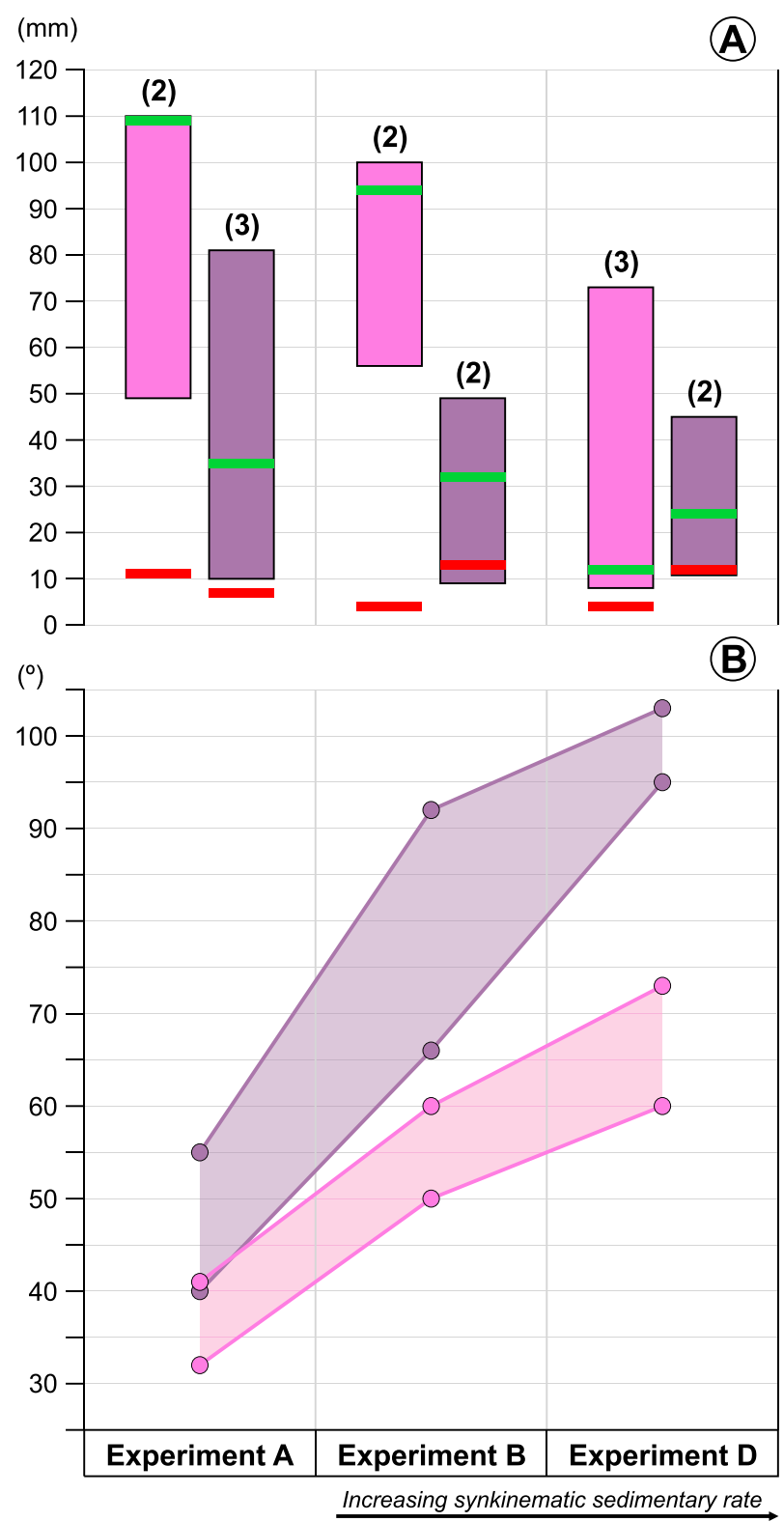

(B)

\section{(A) Displacement range of the thick-skinned inactive thrusts}

Experiment areas with a higher sand proportion in the prekinematic weak layer

Experiment areas with a lower sand proportion in the prekinematic weak layer

Displacement of the active thrust at the end of the experiment

Displacement of the youngest inactive thrust at the end of the experiment

(B) Dip range of the forelimb of the thick-skinned imbricate thrust system

Experiment areas with a higher sand proportion in the prekinematic weak layer

Experiment areas with a lower sand proportion in the prekinematic weak layer

Figure 9. A displacement range of the thick-skinned inactive thrusts at the end of shortening. The horizontal axis indicates the model (a, B, and D), and the vertical axis represents displacement (in $\mathrm{mm}$ ). B dip range of the forelimb of the thick-skinned imbricate thrust system at the end of shortening. The horizontal axis indicates the model (a, B, and D), and the vertical axis represents dip range (in ${ }^{\circ}$ ). 
negligible at the end of the experiment (Structure 1 in Figure 6(a)). During this evolution, the shifting of the deformation front was gradual along a soft transfer zone in which the folds detached at the prekinematic weak layer lost amplitude and eventually died out toward the west. The structures detached over the synkinematic décollement form perpendicular to the shortening direction until deformation reaches the foreland pinch-out (Figure 6(a)). When this happens, the foreland pinch-out is activated, and the frontal structure becomes parallel to the edge of the pure polymer.

It is worth mentioning the intrapolymer deformation recorded by the yellow sandy marker. In general, it was characterized by broken pieces with tight isoclinal folds without a dominant vergence. Moreover, it was slightly thickened in the anticline cores and close to the thick-skinned thrust front and thinned without apparent horizontal shearing in the synclines (Figure 6(b)).

\subsection{Experiments With Continuous Synkinematic Sedimentation}

Synkinematic sedimentation was incorporated into the next set of experiments, with the deposition rate increasing from Experiments B to D. Only those with the lowest and highest rates (Experiments B and D) will be described below. Experiment $\mathrm{C}$ will not be explained in this section since its results match those derived from analysis of the other two. However, it will be displayed in a later section because it best mimics the geometries seen in the Kuqa Basin.

\subsubsection{Low Sedimentation Rate (Experiment B)}

In this synorogenic depositional scenario, shortening triggered the formation of a contractional wedge similar to that of Experiment A but with some differences in external shape and internal structure that were significantly greater in the outer than in the inner domain (Figure 7(b)). Synkinematic sedimentation did not modify the deformation style and kinematics of the inner thick-skinned domain; instead, it produced only a decrease in the displacements of the middle and lower (younger) forethrusts and, as a result, a steepening of the dip of the thrust wedge forelimb (Figures 7(b) and 9). Conversely, in the outer thin-skinned domain, synkinematic sedimentation not only modified the wedge shape and thrust displacements but also induced substantial changes in the distribution of structures and the deformation style above both the prekinematic and synkinematic weak layers.

Two changes are related to structures developed above the deeper, prekinematic décollement. First, there was more hinterland deformation to the west, where the layer was stronger, compared to what was observed in Experiment A. A new forethrust evolved from an asymmetric anticline detached at that level and was truncated by a near-horizontal splay of the overlying thick-skinned thrust (Figure 7(b), Section $\mathrm{Y}^{-} \mathrm{Y}^{\prime}$ ). Thus, it was a relatively old structure that predated development of this thick-skinned thrust. Second, the distribution of structures also changed significantly to the east, where the décollement was weaker (Figure 7(b), Section $\mathrm{X}-\mathrm{X}^{\prime}$ ). Almost all shortening transferred to the forethrust developed at the foreland pinch-out and small amount of internal deformation occurred in the overburden of the prekinematic weak layer. Thus, most of the detachment folds and thrusts of Experiment A did not develop. Moreover, the displacement on this frontal thrust increased considerably from 2 to $9 \mathrm{~cm}$ (cf. Sections X-X' in Figures 6(b) and $7(b))$.

Deformation above the overlying synkinematic polymer layer was modified in a similar way by progressive synkinematic sedimentation. Contractional structures were concentrated at the pinch-outs of this décollement, resulting in a wide, flat-bottomed syncline (Figure 7, top images and Section $\mathrm{Y}-\mathrm{Y}^{\prime}$ ). Moreover, the deformation front migrated very quickly to the foreland pinch-out of the pure polymer (Figure 7, top images and Section $\mathrm{Y}^{-\mathrm{Y}^{\prime}}$ ); in contrast, without synkinematic sedimentation, deformation migrated slowly forward and effectively never reached this location in the western part of the experiment (cf. with Figure 6, top images and Section $\mathrm{Y}^{-\mathrm{Y}^{\prime}}$ ).

Another difference is that in the western parts of the Experiment B, the detachment folds were no longer upright and isoclinal with a roughly constant wavelength, as they were in Experiment A (Figure 6(b), Section $\left.Y-Y^{\prime}\right)$. Instead, they were larger, but narrow open anticlines separated by broad flat-bottomed synclines, with the anticlines slightly truncated and partially transported by small thrusts directed predominantly toward the foreland (Figure 7(b), Section $\mathrm{Y}-\mathrm{Y}^{\prime}$ ). Conversely, the folds to the east, although still larger than in Experiment A, were tight and isoclinal with local development of passive diapirs (Figure 7(b), Section X-X'). 
The western parts of the experiment were affected by late gravitational collapse induced by addition of the postkinematic sand package that commenced at the rear of the contractional wedge. This extensional collapse, detached at the pure polymer layer, led to the forward translation of its overburden marked by the formation of an extensional fault located above the uplifted hinterland portion of the polymer and a forethrust at the foreland pinch-out (Figure 7(b), Section Y-Y'). These two faults had practically the same slip (about $3 \mathrm{~cm}$ ), suggesting that the entire overburden was passively transported without noticeable internal deformation. This allowed us to reconstruct reliably the geometry prior to the collapse and establish that the decoupling between suprapolymer and subpolymer deformation was still significant but less than in Experiment A.

The pure polymer was characterized by a general thickening toward its hinterland edge and a thinning beneath synclines (Figure 6(b)). The intrapolymer sandy marker was generally broken into pieces close to the hinterland pinch-out but was practically continuous toward the foreland. Close-inclined and isoclinaloverturned folds with hinterland and foreland vergence, respectively, were developed in the anticlines cores that bounded the wide syncline (Figure 7(b), Section Y-Y').

\subsubsection{High Sedimentation Rate (Experiment D)}

In this model, with three times the aggradation rate of Experiment B, the structure of the thick-skinned domain did not vary substantially from that with lower sedimentation. The thick-skinned domain continued being a stack of three to four forethrusts with high-angle backthrusts branching off their hanging walls. There was a continuation of the changes seen between Experiments A and B: First, the average displacements of the middle to lower forethrusts further diminished until they were equal to or even lower than that of the uppermost (oldest) forethrust; and second, the forelimb angle of the precinematic thrust stack became near-vertical (Figures 8(b) and 9).

Major changes in deformation style once again took place in the outer domain. For shortening above the prekinematic décollement, this was especially prominent to the west where there was a lower proportion of polymer (Figure 8(b), Cross-section $Y^{\prime} \mathrm{Y}^{\prime}$ ): (1) instead of the hinterland forethrust formed in Experiment B, a tight detachment anticline formed and became decapitated; and (2) more gentle detachment folds formed, with that at the foreland pinch-out increasing its amplitude. These structural changes of decreasing fold amplitude suggest an increase in efficiency of the sandy polymer layer as a décollement. To the east, where the sandy polymer layer had a higher proportion of polymer, the gentle box folds, and doubly vergent thrusts observed at the edge of the thick-skinned thrust stack of the Experiment B were replaced by foreland vergent with low displacement thrusts in Experiment D, foreland-directed at the edge of the thick-skinned thrust stack (cf. Figures 7(b) and 8(b), Section X-X'). Toward the foreland, the overburden was passively transported above the frontal thrust without any significant internal deformation, with the thrust increasing its displacement from 9 to $10.5 \mathrm{~cm}$. The geometry of this frontal thrust also changed: It had no upper flat at the base of the synkinematic polymer, as in previous experiments, but cut up through the overlying sands with a steeper ramp (Figure 8(b), Section $\left.\mathrm{X}-\mathrm{X}^{\prime}\right)$.

Above the synkinematic décollement, detachment folds were substituted with thrusts with the exception of the detachment anticline near the eastern segment of its hinterland pinch-out (Figure 8(b), Section $\mathrm{X}-\mathrm{X}^{\prime}$ ). This fold was still present in this experiment but with a lower interlimb angle and without a piercing diapir. Elsewhere, deformation above the shallow décollement was characterized by foreland-directed thrusts locally linked with secondary backthrusts. These thrusts were more widely spaced that the detachment folds of the previous experiments and their locations were controlled by the spatial distribution of both weak layers: one formed at the frontal pinch-out of the synkinematic décollement and another developed above the contractional structure formed at the foreland pinch-out of the underlying prekinematic weak layer (Figure 8).

As already described, a frontal structure detached at the deep décollement developed only above the eastern, weaker portion of this layer (Structure 1 in Figures 6(a)-8(a)). Its westward propagation into the area where the deep layer was stronger had a profound influence on the deformation above the shallow, synkinematic décollement that is best see in the top views: In Experiment A, a narrow soft transfer zone developed above the boundary between the stronger and weaker deep level (Structure 1 in Figure 6(a)); in Experiment B, shallow structures trend highly obliquely in the soft transfer zone (Structure 1 in Figure 7(a)); and in 


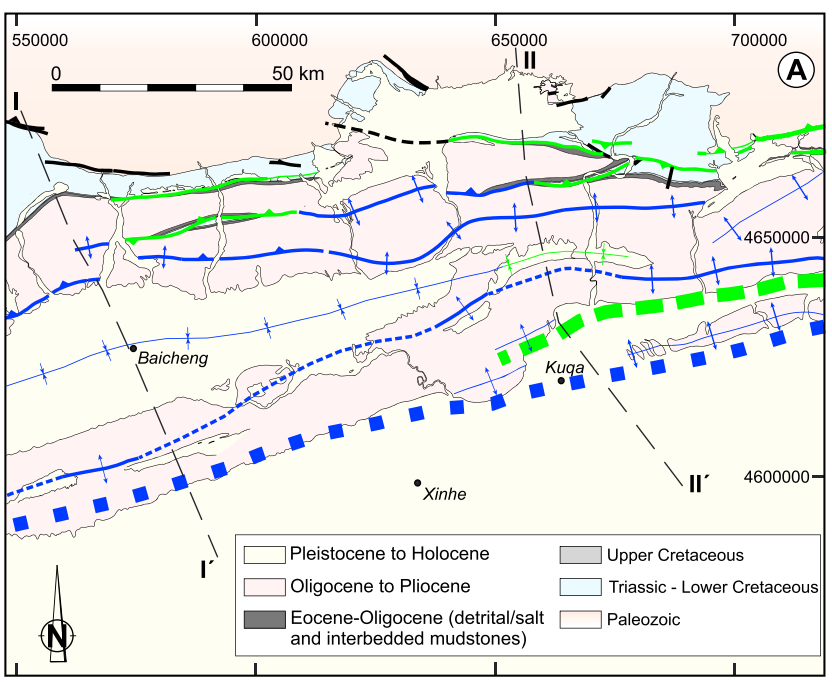

目
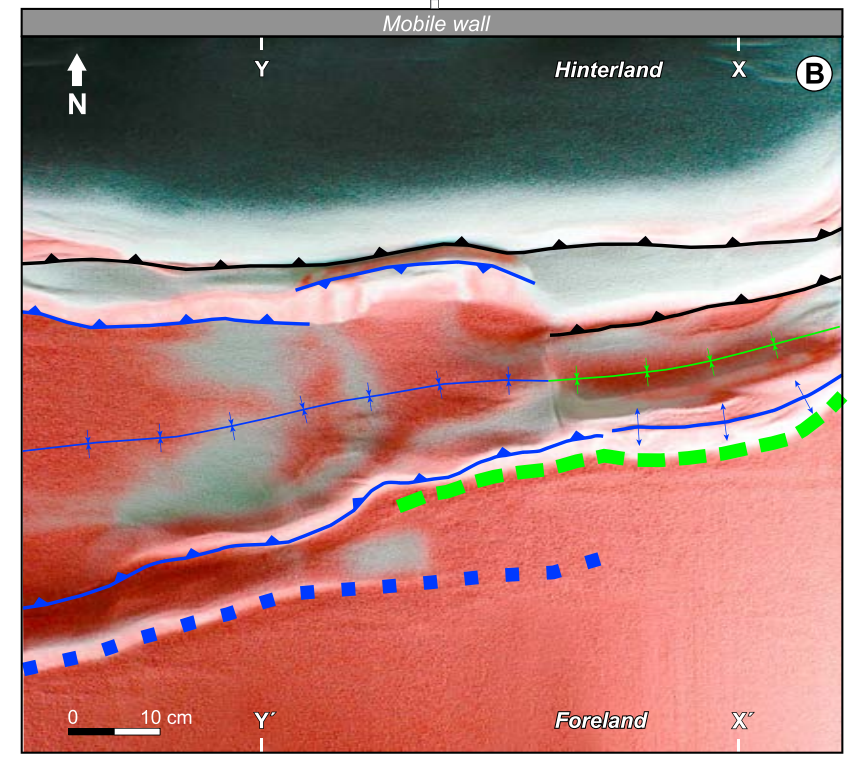

- = - Major foreland deformation front above the prekinematic décollement

... Major foreland deformation front above the synkinematic décollement

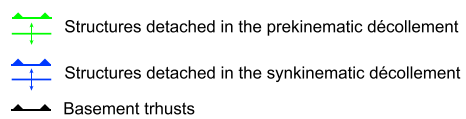

Figure 10. Plan-view comparison between a geological map showing the main structures and deformation fronts of both décollements (modified from Wang et al., 2011; location in Figure 2) and b experiment $\mathrm{C}$ at the end of shortening.
Experiment D, with a higher sedimentation rate, there was wide relay of two nearly parallel contractional structures in this area (Structure 1 in Figure 8(a)).

The top views also depict differences in the evolution of the foreland propagation of deformation above the pure polymer. In Experiment A, deformation only reached the foreland pinch-out in the eastern part of the model, whereas in Experiment B, the frontal structure was already well developed at $15.3 \mathrm{~cm}$ of shortening (cf. Figures 6(a) and 7(a)). However, in Experiment D, more rapid deposition hindered the foreland propagation of deformation above the pure polymer and reached the foreland pinch-out significantly later (cf. Figures 7(a) and 8(a) at $15.3 \mathrm{~cm}$ of shortening) and became well established across the entire model only by the end of the experiment (Figure 8(a)).

The intrapolymer deformation was quite similar as described in the Experiment B. However, it is worth noting that intrapolymer folds showed that there is hindward-directed polymer flow in the internal part underneath a forward-directed thrust with a displacement of almost $4 \mathrm{~cm}$ (Figure 8, Section Y-Y').

\section{Comparison With the Kuqa Fold-and-Thrust Belt}

Comparison of our experimental results with the geometries observed in the central and eastern Kuqa fold-and-thrust belt reveals the strongest similarities with Experiment $\mathrm{C}$, that is, that with a rate of synkinematic sedimentation intermediate between those of Experiments $\mathrm{B}$ and D. Final synkinematic thicknesses in Experiment C $3.3 \mathrm{~cm}$ over the rotation axis) are comparable to those recognized in the hinge zone of the Baicheng syncline or in the Tarim foreland basin, to the South of the Qiulitage frontal structure $(7.0$ and $5.3 \mathrm{~km}$, respectively, that would be analogous to 4.6 and $3.5 \mathrm{~cm}$ in the models if the applied length scale factor is considered). Below, we discuss the similarities and differences between the natural prototype and the analog experiments as depicted in top/map and cross-sectional views (Figures 10 and 11). Note that the western parts of our models correspond to the central part of the Kuqa fold-and-thrust belt, but we will call both the western areas.

There is a noteworthy similarity between the plan-view geometry and spatial arrangement of structures in the Kuqa fold-and-thrust belt and those in Experiment C (Figure 10). In both cases, the fold-and-thrust systems widen to the West: They consist of a northern and a southern structural belts separated by a narrow intervening syncline in the East that becomes broader to the West.

To the west, the salt-detached structures in the Kuqa fold-and-thrust belt are dominantly vergent toward the foreland and are localized at both salt pinch-outs, with a broad, flat-bottomed syncline in between, just as seen in the model (Figure 11(a)). Beneath the hinterland parts of the salt layer, both the Kuqa fold-and-thrust belt and the model have one major thick-skinned thrust that deforms the salt and its overlying structures. In its footwall, there are minor thin-skinned thrusts detached in the organic-rich shales of the prekinematic weak layer that are represented by small folds in the model. To the east, thin-skinned thrusts are better developed in both the organic shalesdetached system and its model equivalent. Above the areally restricted Eocene salt horizon, most deformation is concentrated above the frontal organic shales-detached thrust (Figure 11(b)). Comparison of the cross-section views in Figures 11(a) and 11(b) reveals that the frontalmost structures are located over the synkinematic decollement pinch-out in the West but above the foreland pinch-out of the prekinematic weak layer in the East. This change of position of the main deformation front controls the map view geometry of 

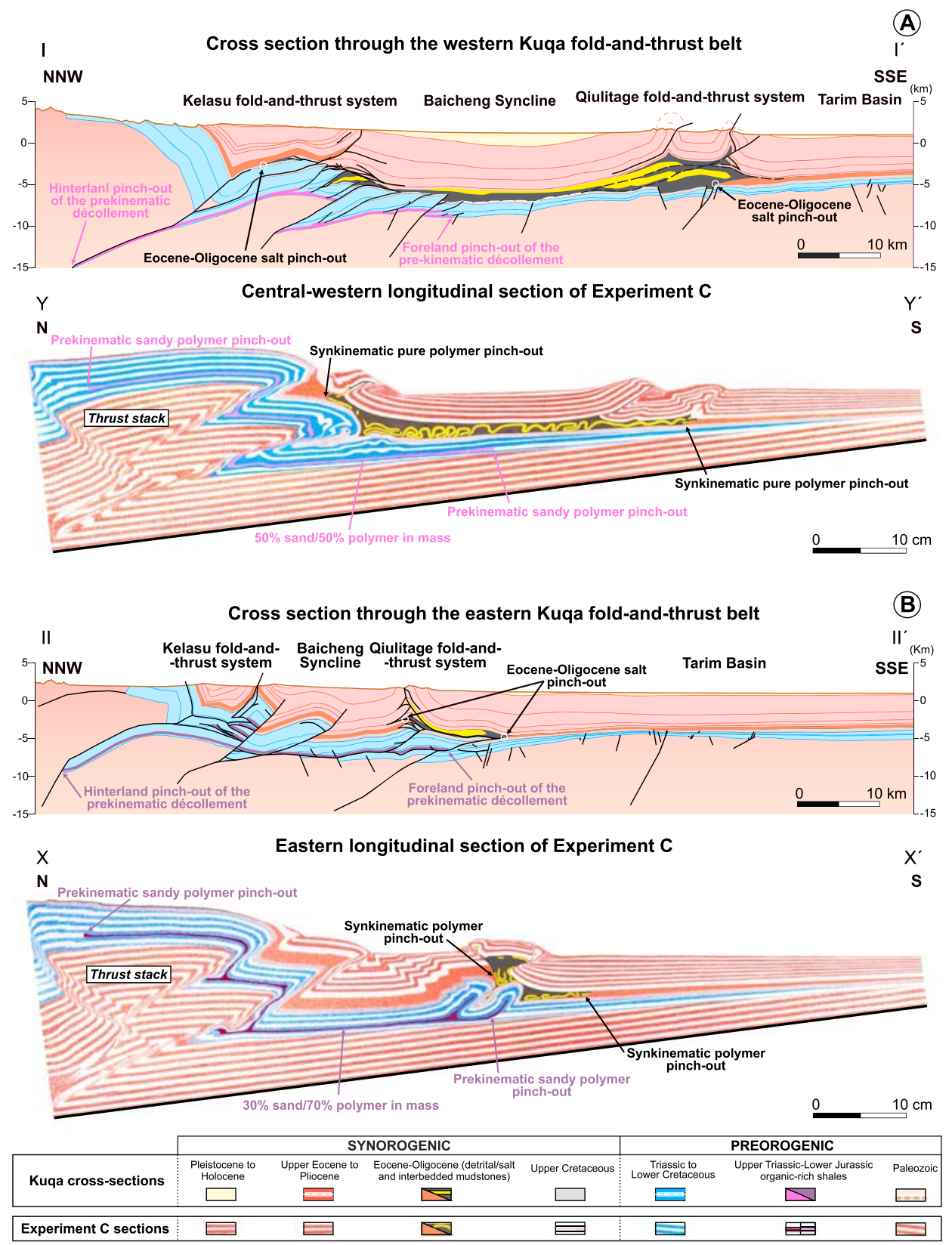

Figure 11. Comparison of seismic-based sections (top) and model sections of experiment C (bottom). A eastern Kuqa foldand-thrust belt and eastern part of model. B central Kuqa fold-and-thrust belt and western part of model (modified from Izquierdo-Llavall et al., 2018). See locations in Figure 10.

the frontal structure (Figure 10) that consists of arcuate structures and an overlapping relay, both in the Kuqa system (Figure 10(a)) and the experiment (Figure 10(b)).

In the case of deformation detached on the prekinematic weak layer, mismatches between model and Kuqa geometries could be partially related to the deformation-rate scaling, but there is no doubt that it is also controlled by a difference between the mechanical behavior of the Upper Triassic-Lower Jurassic organic-rich shales and that of the analog material used in the experimental program. The natural organic-rich shales are in relative terms more viscous than the sand/polymer mixture in the experiments and, unlike this mixture, do not flow at upper crustal levels (Tang et al., 2007; Wang et al., 2011; Wang et al., 2017). Moreover, they may comprise multiple, discrete, and thin detachment levels rather than the single thicker layer of 
sand/polymer mixtures. In any case, thrusts are generated rather than the detachment folds of our experiments (Figure 11).

Differences in deformation above the synkinematic weak layer may be related in part to erosion, which was not modeled in our experimental program. Erosion (i) tends to restrain the forward propagation of deformation fronts (Mugnier et al., 1997), (ii) induces the development of major back-thrusts (Wu \& McClay, 2011), and (iii) influences the active lifetimes of thrusts that remain active for longer periods in the areas unloaded by erosion (Persson \& Sokoutis, 2002). Besides, erosion enhances the effects of differential loading between areas of sediment accumulation and uplifted areas, helping drive migration of salt from beneath the synclines to the anticlines or thrust-fault hanging walls. Therefore, it could explain the coeval Eocene salt inflation in the frontal Qiulitage area and depletion beneath the Baicheng syncline that was not reproduced in our experiments (Figure 11).

Differences in the intrasalt/intrapolymer deformation were probably caused by the model versus real thickness of the interbedded stiff layers. The larger proportional thickness of the natural interlayers ( $\sim .3$ in Kuqa fold-and-thrust belt and $\sim 0.2$ in the experiments) did not allow the formation of tight, short-wavelength buckle folds as generated in the experiments. Instead, gentle folds and thrusts preferentially developed where the salt was inflated, namely, beneath the uplifted areas at the salt pinch-outs (Figure 11).

Finally, differences in the geometry of the basement-involved thrust system largely result from the absence of basement anisotropies in our models. On the contrary, basement units in the Kuqa fold-and-thrust belt are affected by precontractional structures, inherited from Paleozoic and/or Mesozoic times. The reactivation of these features during the Cenozoic strongly controlled the locus and number of basement thrusts and the geometry of the thick-skinned thrust system underlying the décollements (Izquierdo-Llavall et al., 2018).

Despite the mechanical stratigraphy, nature of the detachments, age, duration of contractional deformation, and so forth, the results of our experiments have a direct application to other fold-and-thrust belts with multiple décollement layers, being one of them made by syncontractional salt (Zagros, Pyrenees, Apennines, etc.).

All these fold-and-thrust belts include structural style changes that are controlled by the areal distribution of such detachments and the interaction between them. In particular, they show thrust reentrants, salients, and folds and thrusts trend changes that are related to the areal distribution of the different lithologies susceptible to act as a décollement (i.e., Zagros, Sherkati et al., 2006; and Pyrenees, Vergés et al., 1992).

Also, our experiments depict changes in the taper angle that are linked to the absence or presence of an effective décollement, which can include lateral changes in its rheology. The Pyrenees, (Muñoz et al., 2013) as well as the Sierra Madre Oriental (Marret \& Aranda-Garcia, 2001), show a wide fold-and-thrust belt with a low taper angle where a salt décollement is present. In contrast, in the areas where the salt décollement is not present, the fold-and-thrust belt is narrower with a broader taper angle.

In relation to the role played by synkinematic sedimentation on fold-and-thrust belts with syncontractional salt detachments, our experimental results fit rather well with the observed geometries. High sedimentation rates examples, as the Apennines, also depict localization of the deformation of the hinterland areas of the salt detachment with few and long wavelength structures (Figure 8; Scisciani \& Montefalcone, 2006). Foldand-thrust belts with an intermediate sedimentation rate, as Kuqa (Izquierdo-Llavall et al., 2018) or the Pyrenees (Muñoz et al., 2018), show a large deformation at the foreland pinch-out of the syncontractional salt and a more distributed deformation with folds and thrusts that are also verging toward the foreland (Figure 11). Finally, in natural examples (Sivas Basin and Cyprus Arch) with low to very low sedimentation rates, the deformation does not propagates so faster to the foreland (Kergaravat et al., 2017; Reiche et al., 2015). Here the structural style is characterized by short wavelength structures without a clear vergence that mainly consist in symmetric and asymmetric minibasins separated by tight anticlines that as shortening progress evolve to diapirs (Figure 6).

\section{Discussion}

Analysis of the roles played by various parameters in fold-and-thrust belts with more than one décollement can be rather difficult. The complex structure and kinematics of these belts makes it difficult to identify 


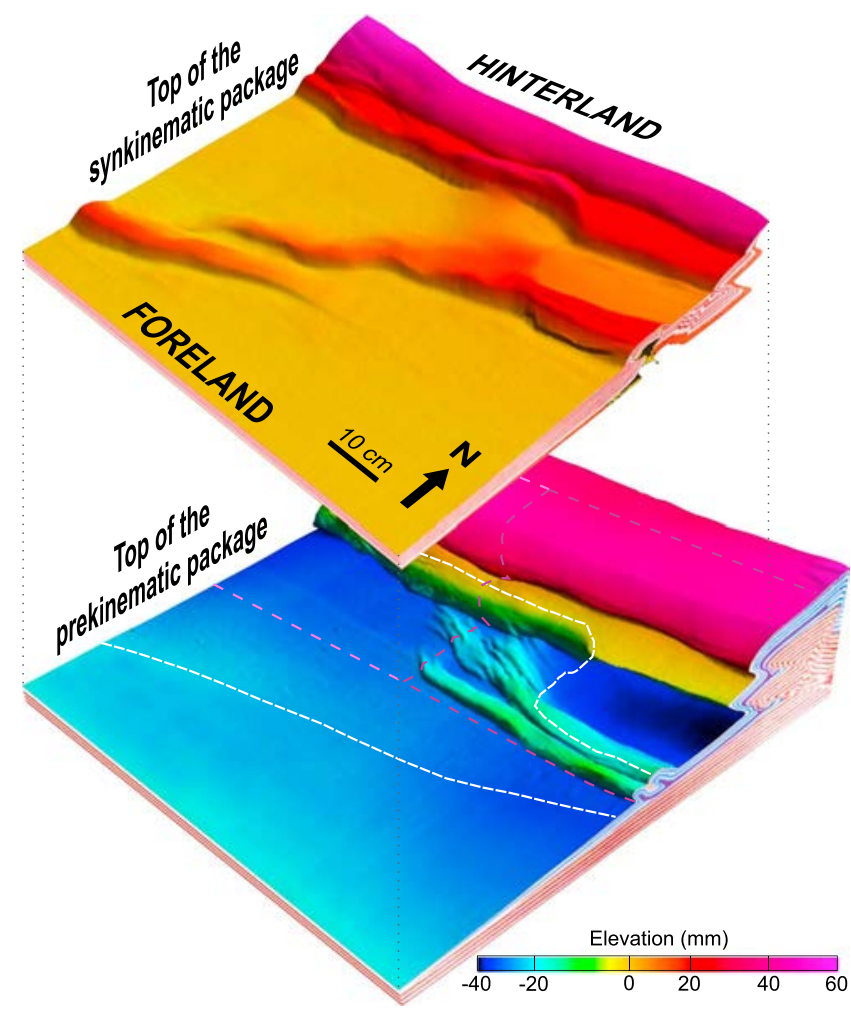

Figure 12. Oblique view of the top of the prekinematic and synkinematic packages at the end of experiment $\mathrm{C}$. note that the deep deformation curves and narrows toward the west, whereas the shallow deformation narrows toward the east. The white dashed line indicates the boundaries of the pure polymer. Purple dashed lines indicate the delineation of the blend of $50 \%$ sand $/ 70 \%$ polymer. Pink dashed lines indicate the delineation of the blend of $50 \%$ sand $/ 50 \%$ polymer. systematic trends and patterns. Moreover, both physical experiments and the Kuqa example show that their structure and kinematics are strongly controlled by the interaction of parameters that work simultaneously but in different ways above each décollement. Hence, before tackling a global analysis of belts with multiple weak horizons, we will isolate and discuss the roles played by weak-layer rheology and sedimentation rate in the deformation developed over the two-individual décollement to latter address.

\subsection{Influence of Weak-Layer Rheology on Thin- and Thick-Skinned Deformation}

As our experimental program shows and as is well known through previous studies (i.e., Allen \& Beaumont, 2012; Bonini, 2003; Gradmann et al., 2009; Luján et al., 2003), the viscosity of the weak layer has a strong impact on the structure and kinematics of overlying thin-skinned deformation. Low-viscosity weak layers (i.e., salt in nature and the pure polymer in our experiments) serve as effective décollements with a high degree of decoupling between the underlying and overlying deformation (Bonini, 2003; Figure 12). They also promote the development of detachment folds without a consistent vergence (Davis \& Engelder, 1985). Depending on several factors such as the thicknesses of the weak layer and its overburden but also erosion of anticline crests (Darnault et al., 2016), they can evolve into salt walls as happened in Experiment A from the present study (Figure 6).

When the viscosity of the weak layer increases, its mechanical behavior changes as the geometry of deformation does. As the viscosity increases, the weak layer is less mobile and becomes less effective as a décollement, and the degree of decoupling between deformation of the underlying and overlying layers decreases (Bonini, 2003). Thus, the higher-viscosity prekinematic layer ( $50 \%$ sand/50\% polymer) was significantly less effective than the $30 \%$ sand $/ 70 \%$ polymer mixture and even less effective than the pure polymer. As a consequence, it maintained coupling much more than the other two analog materials (cf. Sections X-X' and $Y-Y^{\prime}$ in Figure 6(b)).

On the other hand, the increase of resistance to flow in higher viscosity weak layers means that (1) it is more difficult to form both detachment folds and diapirs and (2) the deformation propagates more slowly toward the foreland (Gradmann et al., 2009; Verschuren et al., 1996). For this reason, higher-viscosity décollements promote the formation of thin-skinned thrust systems with a major deformation front located more toward the hinterland than those with lower viscosity décollements. A good example of this is the fold-and-thrust system above the prekinematic weak layer which (1) was characterized by foreland-directed thrusts (Figures 6(b), 7(b), and 8(b)) and (2) a major deformation front located over its foreland pinch-out when the polymer mixture is more effective (30\% sand/70\% polymer) and a deformation front shifted toward the hinterland when the effectivity of the polymer mixture decreases (50\%sand/50\% polymer; Figure 12 , top of the prekinematic sandpack).

Moreover, the prekinematic layer rheology also influences the geometry of the inner thick-skinned domain when it is located above the basement thrust stack. The inner thick-skinned domain was characterized by an antiformal stack when the prekinematic layer has a low viscosity and becomes an imbricate thrust stack when the viscosity increases (Figure 13). As a result, the inner thick-skinned wedge was broader, had a lower elevation, and had a gentler thrust taper angle when the thrust stack was overlain by the high-viscosity weak layer (50\% sand/50\% polymer; Figure 13).

\subsection{Influence of Synkinematic Sedimentation Rate on Thin-Skinned Deformation}

Our experimental program setup was designed in order to analyze the influence of the sedimentation load distribution on the structuring of the fold and thrust system when synkinematic sediments display a 

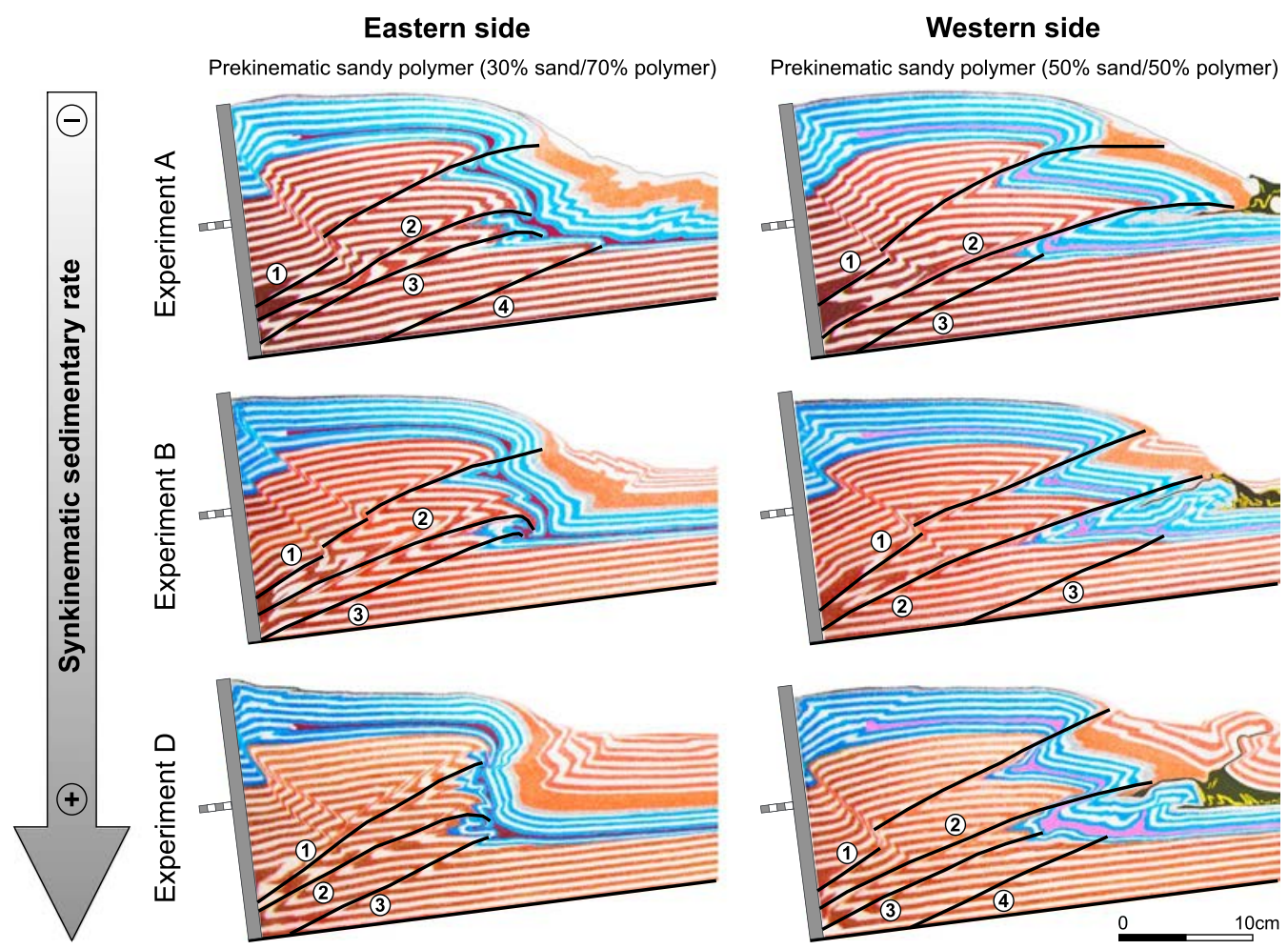

Figure 13. Geometry of the inner thick-skinned domain varying the syntectonic sedimentation rate. Numbers indicate the sequence of thrust development in each experiment.

wedge-shaped geometry. The influence of this distribution on the deformation style and deformation kinematics is discussed below.

\subsubsection{Deformation Style}

The total thickness of overburden above the décollements, whether prekinematic or synkinematic, determines the deformation mechanisms and therefore the structural style (Gutscher et al., 1996; Mugnier et al., 1997), including the geometry, size, number, and spacing of the resulting structures (Barrier et al., 2013; Bonini, 2001; Nalpas et al., 1999; Pichot \& Nalpas, 2009; Storti \& McClay, 1995). In Experiments B-D, the overburden thickness was not constant: It was relatively thin and uniform during the early stages of shortening and then progressively increased over the outer thin-skinned contractional belt and adjoining undeformed areas but at different rates in each experiment. Consequently, the deformation style changed from one experiment to the next and also, albeit subtly, over time in each one. From this, two main general conclusions can be drawn about the influence of synkinematic sedimentation rate on the style of the deformation above a viscous décollement.

First, an increase in the sedimentation rate, and thus the resultant thicker overburden, leads to a decrease in the number of structures as well as an increase of their size. In particular, as shown in the final cross sections (Figures 6(b), 7(b), and 8(b)) and in previous studies (Bonnet et al., 2008; Fillon et al., 2013; Storti \& McClay, 1995), folds have a longer wavelength and greater amplitude, thrusts sheets are thicker and wider, and both thrusts and folds are more widely spaced. Second, different types of structures develop. If the décollement is sufficiently thick and the overburden is relatively thin, shortening is accommodated by detachment folds (Figure 6(b)). As the overburden thickens, however, deformation is progressively accommodated by thrusting rather than folding (Figure 8(b)).

Both effects of varying synkinematic sedimentation rate described above influence the relationship between suprasalt and subsalt/subpolymer deformation. As mentioned before, the location of the major subsalt deformation front (MSDF) was influenced by along-strike variations of the rheology of the prekinematic weak layer. However, the relay zone of the MSDF and the deformation style of the overlying suprasalt structures are controlled by synkinematic sedimentation rate (Figure 14). Increasing synkinematic sedimentation rate 


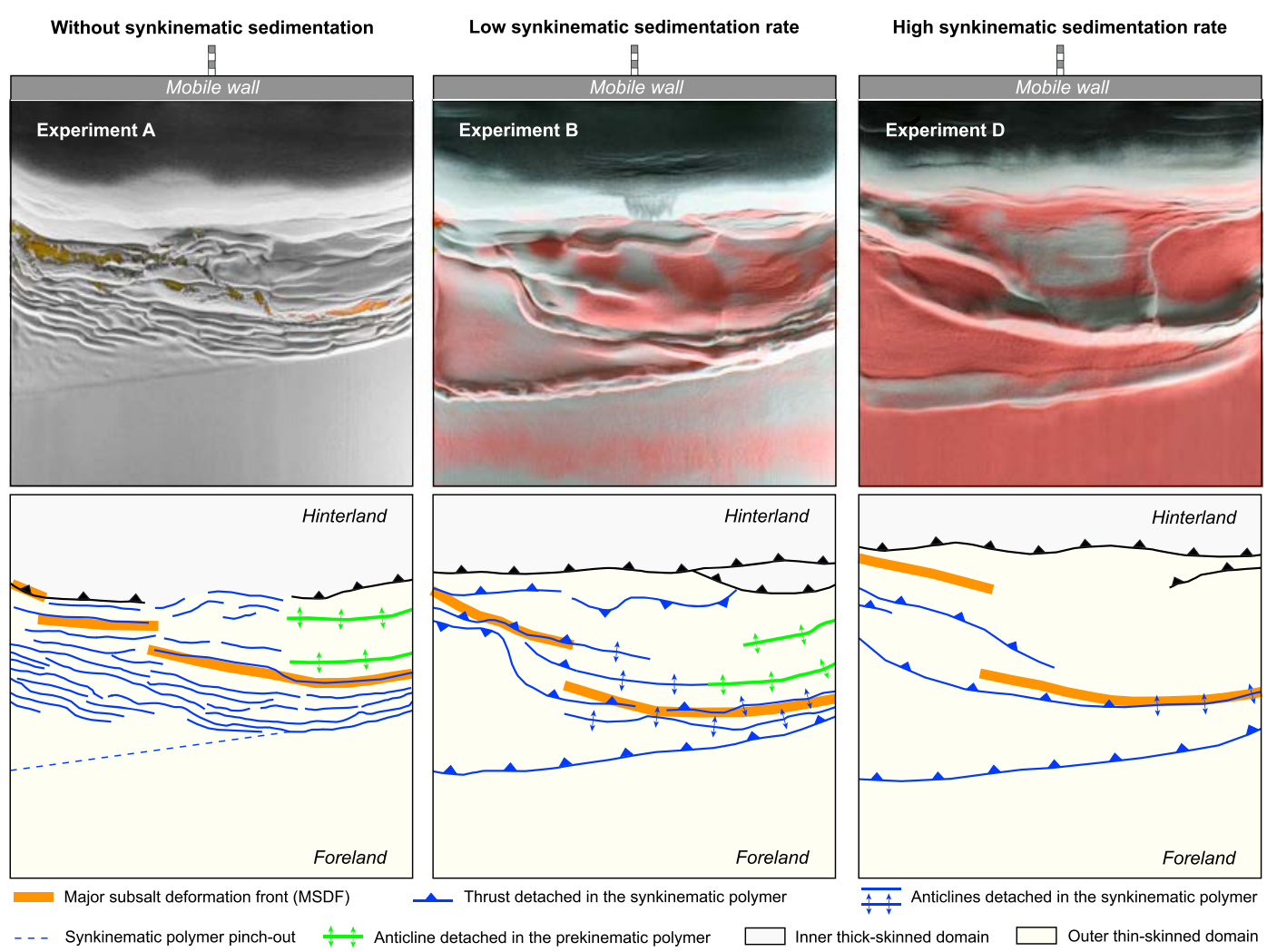

Figure 14. Plan-view comparison between experiments a, B, and D at the end of shortening (top) and their respective structural interpretations showing the suprasalt deformation style in the relay zone of the major subsalt deformation front (bottom).

there is a progressive change from a short relay zone where suprasalt structures formed parallel to the MSDF and can easily link each other to a long transfer zone where suprasalt structures maintain the same orientation but they are overlapped. In between these two extremes (Experiment B), the relay zone showed an intermediate length and suprasalt structures become curved and oblique to the orientation of the MSDF (Figure 14).

The geometry of individual folds and thrusts also evolves as the overburden thickens. First, the transition from one to the other is gradual, so that early detachment folds are often cut and transported by thrusts (Figures 7(b) and 8(b)). Also, as shown in previous work (e.g., Baby et al., 1995; Barrier et al., 2013; Bonnet et al., 2008; Graveleau et al., 2012; Nalpas et al., 1999), folds tighten and thrusts become steeper with an increase of overburden thickness/synkinematic sedimentation rate. For example, the frontal thrust formed at the foreland pinch-out of the prekinematic décollement changed from a ramp-flat geometry under low sedimentation rates (Figure $7(\mathrm{~b})$, Section $\mathrm{X}-\mathrm{X}^{\prime}$ ) to a steeper ramp under high sedimentation rates (Figure 8(b), Section $\left.\mathrm{X}-\mathrm{X}^{\prime}\right)$. Having made these distinctions about the influence of sedimentation rate on structural style, however, it should be kept in mind that similar changes are also influenced by the viscosity and thickness of the weak layer (see previous section). Even with a similar overburden thickness, thick or thin weak layers favor the development of detachment folds or thrust faults, respectively (Costa \& Vendeville, 2002; Nalpas et al., 1999; Steward, 1996).

\subsubsection{Deformation Kinematics}

The overburden thickness generated by the synkinematic sedimentation rate also determines the deformation kinematics and, in particular, the sequence in which structures develop (Baby et al., 1995; Bigi et al., 2010; Bonini, 2001; Fillon et al., 2013; Stockmal et al., 2007; Storti et al., 2000). In our models, the increase of synkinematic sedimentation rate/overburden thickness results in a modification of the deformation kinematics above the synkinematic weak layer/salt similar to that described in previous works (Beaumont et al., 1992; Fillon et al., 2013; Simpson, 2006; Willett, 1999): Formation of short-wavelength folds progresses slowly toward the foreland when the overburden is thin and the sedimentation rate is null (Figures 6(a) 


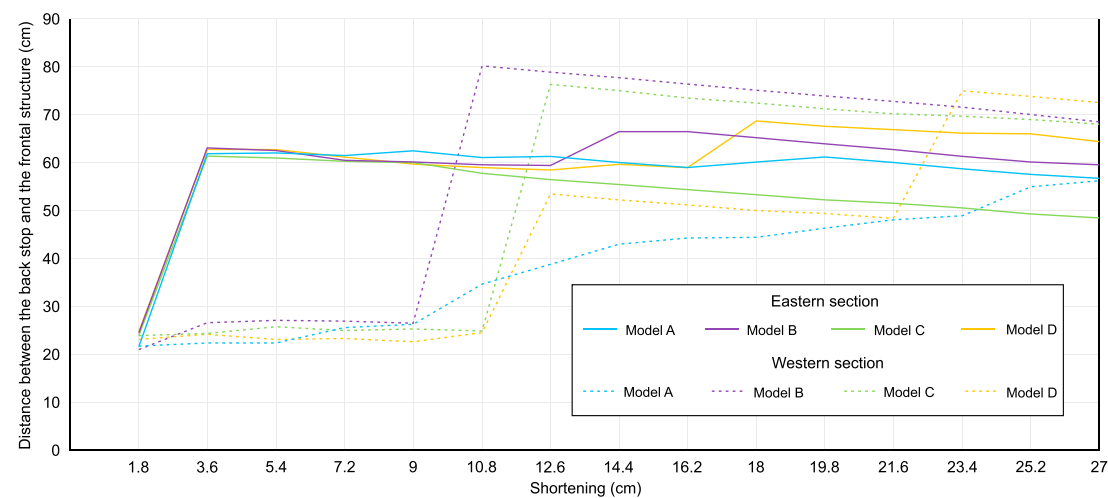

Figure 15. Frontal structure migration during the experiments. The horizontal axis indicates shortening (in $\mathrm{cm}$ ) and vertical axis the distance between the backstop and the frontal structure (in $\mathrm{cm}$ ). Values always taken from the same section (Figures 6(a)-8(a) and 10(b), sections $\mathrm{X}-\mathrm{X}^{\prime}$ and $\mathrm{Y}-\mathrm{Y}^{\prime}$ ).

and 15) but propagates in an effective way as the overburden thickens by an increase of sedimentation rate (Figures 7(a) and 15). Interestingly, high synkinematic sedimentation rate prevents further growth of these frontal structures, and more hinterland structures may be reactivated (Figures 8(b) and 15).

The geometry and kinematics of contractional wedges developed above weak layers are also influenced by the progressive tilting of the models toward the hinterland. Without synkinematic sedimentation, this tilting
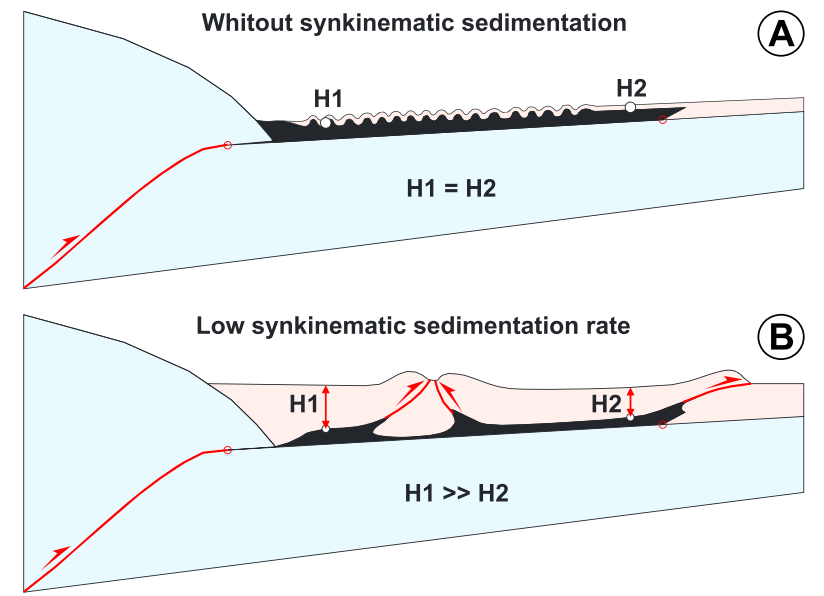

High synkinematic sedimentation rate

(C)

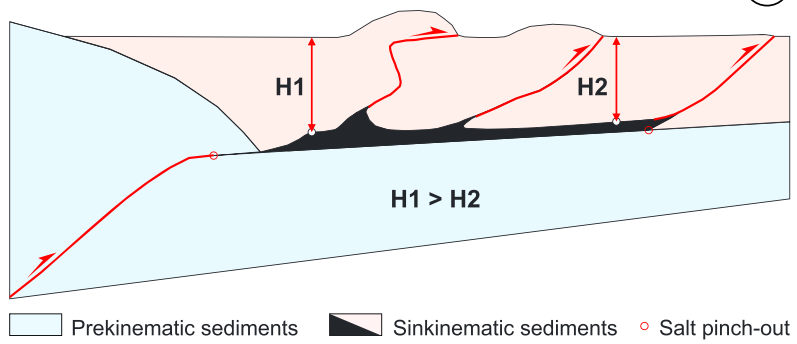

Figure 16. Relation between synkinematic load distribution and nucleation of thrusts at the foreland pinch-out of the salt. A without synkinematic sedimentation, there is no activation of the foreland salt pinch-out. B adding synkinematic sediments favors the activation of the frontal structure. $\mathrm{C}$ increasing synkinematic sedimentation rate decreases the pressure head gradient and delays the activation of the foreland salt pinch-out. $\mathrm{H}=$ vertical thickness. results in shorter, thicker, and steeper contractional wedges whose deformation front migrates very slowly forward (Koyi \& Vendeville, 2003). However, synkinematic sedimentation thickens the hinterland wedge, thereby increasing the taper angle in this area and enhancing the forward propagation of the tip of the thrust wedge and thus the deformation front (Smit et al., 2003; Wu et al., 2014). In this sense, the lack of wedge-shaped synkinematic sediments above the outer thin-skinned domain in Experiment A would partially explain the slow foreland propagation of the deformation above the pure polymer (Figures 6 and 15). This propagation was clearly faster in the experiments with synkinematic sedimentation (Figures 7, 8, and 15).

In other words, the addition of synkinematic sediments promotes propagation of the deformation more quickly toward the foreland pinch-out of the salt. However, considering the same taper angle and wedge-shaped configuration for the synkinematic sandpack applied in our experiments, we noticed that as synkinematic sedimentation rate increases, the vertical thickness gradient decreases, and the development of frontal contractional structures is delayed (Figures 15 and 16).

\subsection{Influence of Synkinematic Sedimentation Rate on Thick-Skinned Deformation}

The total thickness of the overburden and consequently the synkinematic sedimentation rate also determines the kinematics and geometry of deformation in the sandpack of thick-skinned thrusts (Figure 13). First, it reduces the critical taper angle of the wedge by onlapping its forelimb, and second, it hinders foreland propagation of the deformation because it affects the normal stress by increasing the load in the foreland and piggy-back basins (Storti et al., 2000; Storti \& McClay, 1995). Thus, synkinematic sedimentation slows down or even blocks the piggy-back propagation of thrusting, and new thrusts and backthrusts form ahead the leading frontal structure in order to compensate for the reduction of the 
taper angle (Bonini, 2001; Duerto \& McClay, 2009). Accordingly, in our experimental program, the higher the synkinematic sedimentation rate/thickness, the smaller the displacement of the younger, lower thickskinned thrusts will be; as a result, using the top of the prekinematic package as a reference, the wedge of thick-skinned thrusts was narrower and had a steeper forelimb (Figures 9 and 13).

\subsection{Suprasalt/Subsalt Structural Relationships}

The influence of rheology and sedimentation rate/overburden thickness on the cover deformation is valid for both décollements modeled in our experiments as well as for those of the Kuqa fold-and-thrust belt. Consequently, the structural style and deformation kinematics associated with each is different since, among other factors, the rheology and thickness of the overlying rocks is not the same. In general, disharmonic structures develop, with the degree of decoupling of the two levels depending on several factors. The most common are the strain rate, the viscosity and thickness of each décollement, and the thickness of the overburden above each décollement (Borderie et al., 2018; Couzens-Schultz et al., 2003; Gestain et al., 2004; Hudec \& Jackson, 2011; Sherkati et al., 2006), being the last factor different in each model of our experimental program.

In our experimental program and in the Kuqa fold-and-thrust belt, the synkinematic décollement is indeed a very effective decoupling layer that separates two frictional layers with different structures and deformation kinematics (Figure 12). This might suggest that they work independently, but as shown in our study, the structures developed beneath the synkinematic décollement actually have a strong impact on those above this layer. First, the early formed thrusts and folds formed above the weaker (eastern) prekinematic décollement controlled to some degree the areal extent of the synkinematic décollement and thus the fold-and-thrust system detached on it. Second, the same early structures generate topographic highs and thus areas of thinner synkinematic salt/polymer (Figure 5); these hamper the foreland propagation of shallow deformation in that they act as a barriers that induce the formation of major thrusts and folds (Figure 8, Section $\mathrm{X}-\mathrm{X}^{\prime}$ ).

A similar effect is produced when the structures above the lower décollement form after sedimentation of the synkinematic salt/polymer. The geometry of these new thrusts in turn has a strong impact on deformation above the upper décollement. Where these thrusts form flats, deformation above the upper décollement consists of detachment folds and thrusts developed over both this flat and the frontal subsalt structure (Figures 6 and 7, Sections X-X'). If, however, they form simple ramps, all deformation above the upper weak layer is accommodated by the formation of a fault-propagation fold (Figure 8, Section X-X'). The development of subsalt ramps or flats is dependent not only on the rheology and effectiveness of the upper weak layer but also on the synkinematic sedimentation rate. Thus, low to medium synkinematic sedimentation rates promote the formation of subpolymer staircase-shaped thrusts with an upper flat located in the upper weak layer (Figures 6 and 7, Sections $X-X^{\prime}$ ), and high sedimentation rates favor the formation of higher-angle subpolymer thrusts that cut the shallow décollement (Figure 8, Section X-X').

In the above analysis, the prekinematic décollement is regarded to be continuous, uniformly thick, and tilted slightly toward the hinterland prior to the onset of contractional deformation. In addition, there is no consideration of any preexisting structures. Therefore, the models and discussion address a simple scenario that does not match perfectly with most real cases (i.e., Zagros, Apennines, Pyrenees, and even the Tarim Basin). In this sense, it is evident that any departure from these assumptions would have a strong impact on the subsalt contractional deformation and consequently on the suprasalt structures (Callot et al., 2012; Graveleau et al., 2012; Jackson \& Hudec, 2017; Lewis et al., 2013).

\subsection{Internal Deformation of the Salt}

Our experimental program setup includes a sand marker within the pure polymer/salt in order to examine the evolution of the internal structures. The experiments results show that variations in the synkinematic sedimentation rate/overburden thickness apparently do not induce significant changes in the deformation style of the internal structures. Regardless of what sedimentation rate was applied, the strong layer within the salt was always deformed by asymmetric inclined to recumbent folds of similar wavelength and amplitude (Figures 6(b), 7(b), and 8(b)). However, it was more disrupted in the experiment without synkinematic sedimentation in which the salt was deformed by detachment folds and diapirs (Figure 6(b)). 


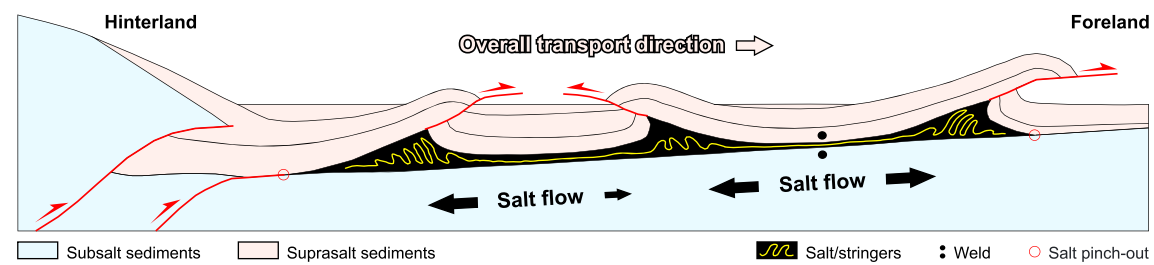

Figure 17. Conceptual sketch based on experiments B-D showing the internal deformation of the salt. Both hinterland and foreland-directed salt flow underneath piggy-back basins. Note that toward the hinterland salt pinch-out, there is hindward-directed salt flow below forward-directed thrusts.

Internal deformation of polymer/salt highlights there is salt evacuation underneath the piggy-back basins (Figures 7(b) and 8(b)). Interestingly, there is hindward-directed salt flow in the internal parts underneath

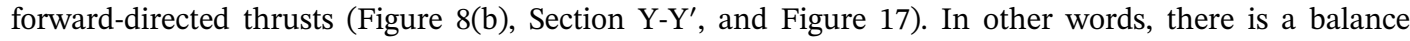
between salt flow related to the thrust emplacement and salt evacuation below the piggy-back basins. Contrary to what was expected, according to our experiments, salt evacuation could prevail over salt flow even though thrusts show displacements of several centimeters $(3.7 \mathrm{~cm})$ in our experiments which is equivalent to displacements of more than $5 \mathrm{~km}$ in the crust (Figure 8(b), Section $\mathrm{Y}-\mathrm{Y}^{\prime}$, and Figure 17).

\section{Conclusions}

The comparison between the analog models of this study and the Kuqa fold-and-thrust belt provides valuable insights on the deformation style in foreland areas of fold-and-thrust belts involving multiple rheologically different décollements. In particular, we examine how both the rate of synkinematic sedimentation and décollement rheology influence fold-and-thrust belts with synorogenic salt and a deeper, preorogenic frictionless lithology (i.e., organic-rich shales).

With respect to the outer, thin-skinned domain, considering wedge-shaped configuration for the synkinematic sandpack applied in our experiments, we conclude the following:

1. Increasing synkinematic sedimentation rate generates a progressive change from distributed shortening with development of several small wavelength and closely spaced structures to fold-and-thrusts systems where deformation is localized into few, longer wavelength fault-related folds located over décollement boundaries.

2. The addition of synkinematic sediments promotes propagation of the deformation more quickly toward the foreland pinch-out of the salt. However, increasing synkinematic sedimentation rate delays the development of frontal contractional structures and favors the formation and reactivation of more hinterland thrusts and backthrusts.

In addition to influencing the thin-skinned part of the contractional wedge, synkinematic sedimentation and décollement rheology are also predominant factors controlling the shape and deformation style of the hinterland, thick-skinned thrust stack.

1. The rheology of the deeper décollement influences the structuring of the inner, thick-skinned domain when the deeper décollement overlies the thrust stack. As viscosity increases, the geometry of the thrust stack changes from an antiformal stack to an imbricate thrust stack. As a result, the inner thick-skinned wedge becomes broader and lower and has a gentler thrust taper angle.

2. Higher synkinematic sedimentation rates and thicknesses result in smaller displacement of the younger (lower) thick-skinned thrusts.

In addition to the different deformation modes above each décollement, there are interactions between the two.

1. The distribution of the deformation above the deeper décollement, controlled in part by its thickness and rheology, can generate structures that, first, determine the areal extent of the salt and therefore of any fold-and-thrust system detached on it and, second, hamper or even prevent the progressive foreland propagation of deformation above the salt. 
2. The degree of decoupling, which is partially dependent on the thickness difference between the overlying and underlying frictional sequences, changes through time as synkinematic sedimentation increases the thickness of the strata above the salt.

3. The relay zone of the MSDF, controlled by synkinematic sedimentation and rheology, determines the geometry of the suprasalt structures. Increasing the length of the relay zone, the suprasalt deformation change from structures formed parallel to the MSDF that easily link each other, then structures that become curved and oblique to the MSDF, and finally, overlapped structures that form again parallel to the MSDF.

Moreover, regarding the internal deformation of the polymer/salt, we can conclude that

1. There is a balance between salt flow related to the thrust emplacement and salt evacuation below the piggy-back basins. Contrary that was expected, the second one could prevail over the first one even though thrusts show kilometric displacements.

Acknowledgments

This research is the result of a fruitful collaboration between the Tarim Oilfield Company (PetroChina) and the GEOMODELS Research Institute. It was funded primarily by the China National Petroleum Company and, secondarily, by the CGL2014-54118-C2 1-R and CGL2017-85532-P (MINECO/ FEDER, UE) projects and the Grup de Recerca de Geodinàmica i Anàlisi de Conques (2014SRG467). The experimental program was executed at the GEOMODELS Analogue Modeling Laboratory which was supported by a Scientific Infrastructure grant (UNBA08-4E-006) provided by the European Regional Development Fund of the Ministerio de Ciencia e Innovación of the Spanish Government and Statoil. We also thank Maria Roma and Frederic-Oriol Escosa for logistical support in the modeling laboratory. Paradigm $^{\mathrm{MT}}$, Midland Valley, and IHS are also acknowledged for providing the GoCad, Move, and Kingdom Suite software, respectively. The data used in this work are listed in the references, text, and figures in the manuscript. We thank the careful review of Leandro Cruz and Alexandra Hatem which helped us to improve the present manuscript.

\section{References}

Allen, J., \& Beaumont, C. (2012). Impact of inconsistent density scaling on physical analogue models of continental margin scale salt tectonics. Journal of Geophysical Research, 17, B08103. https://doi.org/10.1029/2012JB009227

Baby, P., Colletta, B., \& Zubieta, D. (1995). Etude géométrique et expérimentale d'un basin transporté: exemple du synclinorium de l'Alto Beni (Andes centrales). Bulletin de la Société Géologique de France, 166(6), 797-811.

Bally, A. W., Gordy, P. L., \& Stewart, G. A. (1966). Structure, seismic data, and orogenic evolution of southern Canadian Rocky Mountains. Bulletin of Canadian Petroleum Geology, 14(3), 337-381.

Barrier, L., Nalpas, T., Gapais, D., \& Proust, J. N. (2013). Impact of synkinematic sedimentation on the geometry and dynamics of compressive growth structures: Insights from analogue modelling. Tectonophysics, 608, 737-752. https://doi.org/10.1016/j.tecto.2013.08.005

Beaumont, C., Fullsack, P., \& Hamilton, J. (1992). Erosional control of active compressional orogens. In K. R. McClay (Ed.), Thrust Tectonics, (pp. 1-18). London: Chapman \& Hall. https://doi.org/10.1007/978-94-011-3066-0_1

Beaumont, C., Muñoz, J. A., Hamilton, J., \& Fullsack, P. (2000). Factors controlling the alpine evolution of the Central Pyrenees inferred from a comparison of observations and geodynamical models. Journal of Geophysical Research, 105(B4), 8121-8145. https://doi.org/ 10.1029/1999JB900390

Bigi, S., Di Paolo, L., Vadacca, L., \& Gambardella, G. (2010). Load and unload as interference factor on cyclical behavior and kinematics of coulomb wedges: Insights from sandbox experiments. Journal of Structural Geology, 32(1), 28-44. https://doi.org/10.1016/j. jsg.2009.06.018

Bonini, M. (2001). Passive roof thrusting and forelandward fold propagation in scaled brittle-ductile physical models of thrust wedges. Journal of Geophysical Research, 106(B2), 2291-2311. https://doi.org/10.1029/2000JB900310

Bonini, M. (2003). Detachment folding fold amplification, and diapirism in thrust wedge experiments. Tectonics, 22(6), 1065. https://doi. org/10.1029/2002TC001458

Bonnet, C., Malavieille, J., \& Mosar, J. (2008). Surface processes versus kinematics of thrust belts: Impact on rates of erosion, sedimentation, and exhumation-insights from analogue models. Bulletin de la Société Géologique de France, 179(3), 179-192.

Borderie, S., Graveleau, F., Witt, C., \& Vendeville, B. (2018). Impact of an interbedded viscous décollement on the structural and kinematic coupling in fold-and-thrust belts: Insights from analogue modeling. Tectonophysics, 722, 118-137. https://doi.org/10.1016/j. tecto.2017.10.019

Cai, J., \& Lü, X. (2015). Substratum transverse faults in Kuqa Foreland Basin, Northwest China and their significance in petroleum geology. Journal of Asian Earth Sciences, 107, 72-82. https://doi.org/10.1016/j.jseaes.2015.03.012

Callot, J.-P., Trocmé, V., Letouzey, J., Albouy, E., Jahani, S., \& Sherkati, S. (2012). Pre-existing salt structures and the folding of the Zagros Mountains. In G. I. Alsop, S. G. Archer, A. J. Hartley, N. T. Grant, \& R. Hodgkinson (Eds.), Salt Tectonics, Sediments and Prospectivity, Special Publications, (Vol. 363, pp. 545-561). London: Geological Society.

Cartwright, J., Jackson, M. P., Dooley, T., \& Higgins, S. (2012). Strain partitioning in gravity-driven shortening of a thick, multilayered evaporate sequence. In G. I. Alsop, S. G. Archer, A. J. Hartley, N. T. Grant, \& R. Hodgkinson (Eds.), Salt Tectonics, Sediments and Prospectivity, Special Publications, (Vol. 363, pp. 449-470). London: Geological Society.

Chapman, J. B., \& DeCelles, P. G. (2015). Foreland basin stratigraphic control on thrust belt evolution. Geology, 43(7), 579-582. https://doi. $\operatorname{org} / 10.1130 / \mathrm{G} 36597.1$

Charreau, J., Gilder, S., Chen, Y., Dominguez, S., Avouac, J. P., Sen, S., et al. (2006). Magnetostratigraphy of the Yaha section, Tarim Basin (China): 11 Ma acceleration in erosion and uplift of the Tian Shan Mountains. Geology, 34(3), 181-184. https://doi.org/10.1130/G22106.1

Chen, S., Tang, L., Jin, Z., Jia, C., \& Pi, X. (2004). Thrust and fold tectonics and the role of evaporites in deformation in the Western Kuqa foreland of Tarim Basin, Northwest China. Marine and Petroleum Geology, 21(8), 1027-1042. https://doi.org/10.1016/j. marpetgeo.2004.01.008

Cobbold, P. R., Davy, P., Gapais, D., Rossello, E. A., Sadybakasov, E., Thomas, J. C., et al. (1993). Sedimentary basins and crustal thickening. Sedimentary Geology, 86(1-2), 77-89. https://doi.org/10.1016/0037-0738(93)90134-Q

Cobbold, P. R., Durant, S., \& Mourgues, R. (2001). Sandbox modelling of thrust wedges with fluid-assisted detachments, Tectonophysics, 334, 245-258. https://doi.org/10.1016/S0040-1951(01)00070-1

Costa, E., \& Vendeville, B. C. (2002). Experimental insights on the geometry and kinematics of fold-and-thrust belts above weak, viscous evaporitic décollement. Journal of Structural Geology, 24(11), 1729-1739. https://doi.org/10.1016/S0191-8141(01)00169-9

Cotton, J., \& Koyi, H. A. (2000). Modelling of thrust fronts above ductile and frictional décollements; examples from the salt range and Potwar plateau, Pakistan. Geological Society of America Bulletin, 112(3), 351-363. https://doi.org/10.1130/0016-7606(2000)112<351: MOTFAD $>2.0 . \mathrm{CO} ; 2$

Couzens-Schultz, B. A., Vendeville, B. C., \& Wiltschko, D. V. (2003). Duplex Style and Triangle Zone Formation: Insights from Physical Modeling. Journal of Structural Geology, 25(10), 1623-1644. https://doi.org/10.1016/S0191-8141(03)00004-X 
Darnault, R., Callot, J. P., Ballard, J. F., Fraisse, G., Mengus, J. M., \& Ringerbach, J. C. (2016). Control of syntectonic erosion and sedimentation on kinematic evolution of a multidecollement fold and thrust zone: Analogue modeling of folding in the southern subandean of Bolivia. Journal of Structural Geology, 89, 30-43. https://doi.org/10.1016/j.jsg.2016.05.009

Davis, D. M., \& Engelder, T. (1985). The role of salt in fold and thrust belts. Tectonophysics, 119(1-4), 67-88. https://doi.org/10.1016/00401951(85)90033-2

Davis, D. M., Suppe, J., \& Dahlen, F. A. (1983). Mechanics of fold-and-thrust belts and accretionary wedges. Journal of Geophysical Research, 88, 377-378. https://doi.org/10.1029/JB088iB02p01153

DeCelles, P. G., \& Giles, K. N. (1996). Foreland basin systems. Basin Research, 8(2), 105-123. https://doi.org/10.1046/j.13652117.1996.01491.x

Del Castello, M., Pini, G. A., \& McClay, K. (2004). Effect of unbalanced topography and overloading on coulomb wedge kinematics: Insights from sandbox modeling. Journal of Geophysical Research, 109, B05405. https://doi.org/10.1029/2003JB002709

Dell'Ertole, T., \& Schellart, W. (2013). The development of sheath folds in viscously stratified materials in simple shear conditions: An analogue approach. Journal of Structural Geology, 56, 129-141. https://doi.org/10.1016/j.jsg.2013.09.002

Driehaus, L., Nalpas, T., \& Ballard, J. F. (2014). Interaction between deformation and sedimentation in a multidecollement thrust zone: Analogue modeling and application to the sub-Andean thrust belt of Bolivia. Journal of Structural Geology, 65, 59-68. https://doi.org/ 10.1016/j.jsg.2014.04.003

Duerto, L., \& McClay, K. (2009). The role of syntectonic sedimentation in the evolution of doubly vergent thrust wedges and foreland folds Marine and Petroleum Geology, 26(7), 1051-1069. https://doi.org/10.1016/j.marpetgeo.2008.07.004

Ferrer, O., Gratacós, O., Roca, E., \& Muñoz, J. A. (2017). Modeling the interaction between presalt seamounts and gravitational failure in salt-bearing passive margins: The Messinian case in the northwestern Mediterranean Basin. Interpretation, 5, 99-117.

Fillon, C., Huismans, R. S., \& van der Beek, P. (2013). Syntectonic sedimentation effects on the growth of fold-and-thrust belts. Geology, 41(1), 83-86. https://doi.org/10.1130/G33531.1

Gestain, V., Nalpas, T., Rouby, D., \& Barrier, L. (2004). Rôle des niveaux incompétents syn-cinemátiques sur l'évolution des zones chevauchantes-modélisations analogiques. Bulletin de la Société Géologique de France, 175(4), 351-359. https://doi.org/10.2113/ 175.4.351

Goncharov, M. A. (2010). Applicability of similarity conditions to analogue modelling of tectonic structures. Geodynamics \& Tectonophysics, 1(2), 148-168. https://doi.org/10.5800/GT-2010-1-2-0012

Gradmann, S., Beaumont, C., \& Albertz, M. (2009). Factors controlling the evolution of the Perdido Fold Belt, northwestern golf of Mexico, determined from numerical models. Tectonics, 28, TC2002. https://doi.org/10.1029/2008TC002326

Graveleau, F., \& Dominguez, S. (2008). Analogue modelling of the interactions between tectonics, erosion and sedimentation in foreland thrust belts. Comptes Rendus Geoscience, 340(5), 324-333. https://doi.org/10.1016/j.crte.2008.01.005

Graveleau, F., Malavieille, J., \& Dominguez, S. (2012). Experimental modelling of orogenic wedges: A review. Tectonophysics, 538-540, 1-66 . https://doi.org/10.1016/j.tecto.2012.01.027

Guo, X., Liu, K., Jia, C., Song, Y., Zhao, M., \& Lu, X. (2016). Effects of early petroleum charge and overpressure on reservoir porosity preservation in the giant Kela-2 gas field, Kuqa depression, Tarim Basin, Northwest China. American Association of Petroleum Geologist Bulletin, 100(02), 191-212. https://doi.org/10.1306/11181514223

Gutscher, M. A., Kukowski, N., Malavieille, J., \& Lallemand, S. (1996). Cyclical behavior of thrust wedges: Insights from high basal friction sandbox experiments. Geology, 24(2), 135-138. https://doi.org/10.1130/0091-7613(1996)024<0135:CBOTWI >2.3.CO;2

He, D., Zhou, X., Yang, H., Lei, G., \& Ma, Y. (2009). Geological structure and its controls on giant oil and gas fields in Kuqa depression, Tarim Basin: A clue from new shot seismic data. Geotectonica et Metallogenia, 1, 19-32.

Huang, B., Piper, J. D. A., Peng, S., Liu, T., Li, Z., Wang, Q., \& Zhu, R. (2006). Magnetostratigraphic study of the Kuche depression, Tarim Basin, and Cenozoic uplift of the Tian Shan range, western China. Earth and Planetary Science Letters, 251(3-4), 346-364. https://doi. org/10.1016/j.epsl.2006.09.020

Hubbert, M. K. (1937). Theory of scale models as applied to the study of geologic structures. Bulletin of the Geological Society of America, 48(10), 1459-1520. https://doi.org/10.1130/GSAB-48-1459

Hudec, M. R., \& Jackson, M. P. A. (2011). The salt mine: A digital atlas. American Association of Petroleum Geologists Memoir, 99, 1-305.

Izquierdo-Llavall, E., Roca, E., Huiwen, X., Pla, O., Muñoz, J.A., Rowan, M., et al. (2017). Structural style of a fold-and-thrust belt involving laterally-changing, multiple décollements: The Kuqa fold-and-thrust belt (NW China). In: Fold and thrust belts: Structural style, evolution and exploration. Presented at The Geological Society, Burlington House, London, October-November, Abstract Volume pp. 142.

Izquierdo-Llavall, E., Roca, E., Xie, H., Pla, O., Muñoz, J. A., Rowan, M. G., et al. (2018). Influence of overlapping décollements, syntectonic sedimentation and structural inheritance in the evolution of a contractional system: The central Kuqa fold-and-thrust belt (Tian Shan Mountains, NW China). Tectonics, 37, 2608-2632. https://doi.org/10.1029/2017TC004928

Jackson, M., \& Hudec, M. (2017). Contractional salt-tectonic systems. In Salt Tectonics: Principles and Practice, (pp. 304-335). Cambridge: Cambridge University Press. https://doi.org/10.1017/9781139003988.015

Jaumé, S. C., \& Lillie, R. J. (1988). Mechanics of the salt range-Potwar plateau, Pakistan: A fold-and-thrust belt underlain by evaporites. Tectonics, 7(1), 57-71. https://doi.org/10.1029/TC007i001p00057

Jia, D., Lu, H., Cai, D., Wu, S., Shi, Y., \& Chen, C. (1998). Structural features of northern Tarim basin: Implications for regional tectonics and petroleum traps. American Association of Petroleum Geologists Bulletin, 82(1), 147-159.

Kergaravat, C., Ribes, C., Callot, J.-P., \& Ringenbach, J.-C. (2017). Tectono-stratigraphic evolution of salt-controlled minibasins in a fold and thrust belt, the oligo-Miocene Central Sivas Basin. Journal of Structural Geology, 102, 75-97. https://doi.org/10.1016/j. jsg.2017.07.007

Konstantinosvskaya, E. A., Rodriguez, D., Kirkwood, D., Harris, L. B., \& Thériault, R. (2009). Effects of basement structure, sedimentation and erosion on thrust wedge geometry: An example from the Quebec Appalachians and analogue models. Bulletin of Canadian Petroleum Geology, 57(1), 34-62. https://doi.org/10.2113/gscpgbull.57.1.34

Konstantinovskaya, E. A., \& Malavieille, J. (2011). Thrust wedges with décollement levels and syntectonic erosion: A view from analog models. Tectonophysics, 502(3-4), 336-350. https://doi.org/10.1016/j.tecto.2011.01.020

Koyi, H. A., \& Vendeville, B. C. (2003). The effect of décollement dip on geometry and kinematics of model accretionary wedges. Journal of Structural Geology, 25(9), 1445-1450. https://doi.org/10.1016/S0191-8141(02)00202-X

Krantz, R. W. (1991). Measurements of friction coefficients and cohesion for faulting and fault reactivation in laboratory models using sand and sand mixtures. Tectonophysics, 188(1-2), 203-207. https://doi.org/10.1016/0040-1951(91)90323-K

Labaume, P., \& Moretti, I. (2001). Diagenesis-dependence of cataclastic thrust fault zone sealing in sandstones. Example from the Bolivian Sub-Andean Zone. Journal of Structural Geology, 21, 1659-1675. 
Lammerer, B., Gebrande, H., Lüschen, E., \& Veselá, P. (2008). A crustal-scale cross-section through the Tauern window (eastern Alps). In S Siegesmund, B. Fügenschuh, \& N. Froitzheim (Eds.), Tectonic Aspects of the Alpine-Dinaride-Carpathian System, Special Publications, (Vol. 298, pp. 219-229). London: Geological Society.

Larroque, C., Calassou, S., Malavieille, J., \& Chanier, F. (1995). Experimental modelling of forearc basin development during accretionary wedge growth. Basin Research, 7(3), 255-268. https://doi.org/10.1111/j.1365-2117.1995.tb00109.x

Leturmy, P., Mugnier, J. L., Vinour, P., Baby, P., Colletta, B., \& Chabron, E. (2000). Piggyback basin development above a thin-skinned thrust belt with two detachment levels as a function of interactions between tectonic and superficial mass transfer: The case of the Subandean zone (Bolivia). Tectonophysics, 320(1), 45-67. https://doi.org/10.1016/S0040-1951(00)00023-8

Lewis, M. M., Jackson, C. A. L., \& Gawthorpe, R. L. (2013). Salt-influenced normal fault growth and forced folding: The Stavanger fault system, North Sea. Journal of Structural Geology, 54, 156-173. https://doi.org/10.1016/j.jsg.2013.07.015

Li, J., Webb, A. A. W., Mao, X., Eckhoff, I., Colón, C., Zhang, K., et al. (2014). Active surface salt structures of the western Kuqa fold-thrust belt, northwestern China. Geosphere, 10(6), 1219-1234. https://doi.org/10.1130/GES01021.1

Li, S., Wang, X., \& Suppe, J. (2012). Compressional salt tectonics and synkinematic strata of the western Kuqa foreland basin, southern Tian Shan, China. Basin Research, 24(4), 475-497. https://doi.org/10.1111/j.1365-2117.2011.00531.x

Li, Z., Song, W., Peng, S., Wang, D., \& Zhang, Z. (2004). Mesozoic-Cenozoic tectonic relationships between the Kuqa subbasin and Tian Shan, Northwest China: Constraints from depositional records. Sedimentary Geology, 172(3-4), 223-249. https://doi.org/10.1016/j. sedgeo.2004.09.002

Liu, J., Wang, Q., Lin, C., Zhang, L., Lei, Y., Hu, G., \& Hu, B. (2008). Sequence and systems tract of Paleogene Kumugeliemu Group in Western Kuqa Depression, Tarim Basin. Petroleum Exploration and Development, 35(6), 651-656. https://doi.org/10.1016/S18763804(09)60098-7

Lohrmann, J., Kukowski, N., Adam, J., \& Oncken, O. (2003). The impact of analogue material properties on the geometry, kinematics, and dynamics of convergent sand wedges. Journal of Structural Geology, 25(10), 1691-1711. https://doi.org/10.1016/S0191-8141(03)00005-1

Luján, M., Storti, F., Balanyá, J. C., Crespo-Blanc, A., \& Rossetti, F. (2003). Role of sécollement material with different rheological properties in the structure of the Aljibe thrust imbricate (flysch trough, Gibraltar arc): An analogue modeling approach. Journal of Structural Geology, 25(6), 867-881. https://doi.org/10.1016/S0191-8141(02)00087-1

Lv, D., Liu, J., Wu, X., Yang, Q., Yong, P. (2016). Qapqal coal characteristics analysis of Yinan coalfield in Xinjiang province, western China. International conference on power, energy engineering and management (PEEM 2016). ISBN: 978-1-60595-324-3.

Marret, R., \& Aranda-Garcia, M. (2001). Regional structure of the Sierra Madre oriental fold-thrust belt, Mexico. In R. Marret (Ed.), Genesis and Controls of Reservoir-Scale Carbonate Deformation, Monterrey Salient, Mexico, Guidebook, (Vol. 28, pp. 31-55). Austin: Bureau of Economic Geology.

Massoli, D., Koyi, H., \& Barchi, M. (2006). Structural evolution of a fold and thrust belt generated by multiple décollements: Analogue models and natural examples from the northern Apennines (Italy). Journal of Structural Geology, 28(2), 185-199. https://doi.org/ 10.1016/j.jsg.2005.11.002

McClay, K. R., Whitehouse, P. S., Dooley, T., \& Richards, M. (2004). 3D evolution of fold and thrust belts formed by oblique convergence. Marine and Petroleum Geology, 21(7), 857-877. https://doi.org/10.1016/j.marpetgeo.2004.03.009

Molinaro, M., Leturmy, P., Guezou, J. C., Frizon de Lamotte, D., \& Eshraghi, S. A. (2005). The structure and kinematics of the southeastern Zagros fold-and-thrust belt, Iran: From thin-skinned to thick-skinned tectonics. Tectonics, 24, TC3007. https://doi.org/10.1029/ 2004TC001633

Mount, V. S. (2014). Structural style of the Appalachian plateau fold belt, north-Central Pennsylvania. Journal of Structural Geology, 69, 284-303. https://doi.org/10.1016/j.jsg.2014.04.005

Mourgues, R., \& Cobbold, P. R. (2006). Thrust wedges and fluid overpressures: Sandbox models involving pore fluids. Journal of Geophysical Research, 111, B05404. https://doi.org/10.1029/2004JB003441

Mugnier, J. L., Baby, P., Colletta, B., Vinour, P., Bale, P., \& Leturmy, P. (1997). Thrust geometry controlled by erosion and sedimentation: A view from analogue models. Geology, 25(5), 427-430. https://doi.org/10.1130/0091-7613(1997)025<0427:TGCBEA>2.3.CO;2

Muñoz, J. A. (1992). Evolution of a continental collision belt: ECORS-Pyrenees crustal balanced section. In K. R. McClay (Ed.), Thrust Tectonics, (pp. 235-246). London: Chapman \& Hall. https://doi.org/10.1007/978-94-011-3066-0_21

Muñoz, J. A., Beamud, E., Fernández, O., Arbués, P., Dinarès-Turull, J., \& Poblet, J. (2013). The Ainsa fold and thrust oblique zone of the Central Pyrenees: Kinematics of a curved contractional system from paleomagnetic and structural data. Tectonics, 32, 1142-1175. https://doi.org/10.1002/tect.20070

Muñoz, J. A., Mencos, J., Roca, E., Carrera, N., Gratacós, O., Ferrer, O., \& Fernández, O. (2018). The structure of the South-CentralPyrenean fold and thrust belt as constrained by subsurface data. Geologica Acta, 16(4), 439-460.

Nalpas, T., Györfy, I., Guillocheau, F., Lafont, F., \& Homewood, P. (1999). Influence de la charge sédimentaire sur le développement d'anticlinaux synsédimentaires. Modélisation analogique et exemple de terrain (bordure sud du bassin de Jaca). Bulletin de la Société Géologique de France, 170(5), 733-740.

Neng, Y., Xie, H., Yin, H., Li, Y., \& Wang, W. (2018). Effect of basement structure and salt tectonics on deformation styles along strike: An example from the Kuqa fold-and-thrust belt, West China. Tectonophysics, 730, 114-131. https://doi.org/10.1016/j.tecto.2018.02.006

Persson, K. S., Garcia-Castellanos, D., \& Sokoutis, D. (2004). River transport effects on compressional belts: Firsts results from an integrated analogue-numerical model. Journal of Geophysical Research, 109, B01409. https://doi.org/10.1029/2002JB002274

Persson, K. S., \& Sokoutis, D. (2002). Analogue models of orogenic wedges controlled by erosion. Tectonophysics, 356(4), 323-336. https:// doi.org/10.1016/S0040-1951(02)00443-2

Pichot, T., \& Nalpas, T. (2009). Influence of synkinematic sedimentation in a thrust system with two decollement levels; analogue modelling. Tectonophysics, 206(2-3), 371-388.

Ping, Y., Longde, S., \& Jiafu, Q. (2016). Key seismic exploration techniques for foreland thrust belt: A case from the complex deep subsalt structure of Kuqa, Tarim Basin, Western China. Interpretation, 4(3), T337-T346. https://doi.org/10.1190/INT-2015-0148.1

Ravaglia, A., Turrini, C., \& Seno, S. (2004). Mechanical stratigraphy as a factor controlling the development of a sandbox transfer zone: A three-dimensional analysis. Journal of Structural Geology, 26(12), 2269-2283. https://doi.org/10.1016/j.jsg.2004.04.009

Reiche, S., Hübscher, C., \& Ehrhardt, A. (2015). The impact of salt on the late Messinian to recent tectonostratigraphic evolution of the Cyprus subduction zone. Basin Research, 28(5), 569-597.

Ruh, J. B., Klaus, B. J. P., \& Burg, J.-P. (2012). Numerical investigation of deformation mechanics in fold-and-thrust belts: Influence of rheology of single and multiple décollements. Tectonics, 31, TC3005. https://doi.org/10.1029/2011TC003047

Sans, M., Muñoz, J. A., \& Vergés, J. (1996). Triangle zone and thrust wedge geometries related to evaporitic horizons (southern Pyrenees). Canadian Petroleum Geology Bulletin, 44(2), 375-384. 
Schellart, W. P. (2000). Shear test results for cohesion and friction coefficients for different granular materials: Scaling implications for their usage in analogue modelling. Tectonophysics, 324(1-2), 1-16. https://doi.org/10.1016/S0040-1951(00)00111-6

Scisciani, V., \& Montefalcone, R. (2006). Coexistence of thin and thick-skinned tectonics: An example from the central Apennines, Italy. In S. Mazzoli, \& R. H. W. Butler (Eds.), Styles of continental contraction, Geological Society of America Special Paper, (Vol. 414, pp. 33-54). Boulder, Colorado: Geological Society of America.

Sherkati, S., Letouzey, J., \& Frizon de Lamotte, D. (2006). Central Zagros fold-thrust belt (Iran): New insights from seismic data, field observations and sandbox modeling. Tectonics, 25, TC4007. https://doi.org/10.1029/2004TC001766

Shuwei, G., Zhuxin, C., Benliang, L., \& Chaojun, Z. (2010). Discussions on the character and interpretation model of Kelasu deep structures in the Kuqa area. Petroleum Exploration and Development, 37(5), 531-536. https://doi.org/10.1016/S1876-3804(10)60053-5

Simpson, G. D. H. (2006). Modelling interactions between fold-thrust belt formation, foreland flexure and surface mass transport. Basin Research, 18(2), 125-143. https://doi.org/10.1111/j.1365-2117.2006.00287.x

Smit, J., Burg, J.-P., Dolati, A., \& Sokoutis, D. (2010). Effects of mass waste events on thrust wedges: Analogue experiments and application to the Makran accretionary wedge. Tectonics, 29, TC3003. https://doi.org/10.1029/2009TC002526

Smit, J. H. W., Brun, J.-P., \& Soukoutis, D. (2003). Deformation of brittle-ductile thrust wedges in experiments and nature. Journal of Geophysical Research, 108(B10), 2480. https://doi.org/10.1029/2002JB002190

Soto, R., Casas, A. M., Storti, F., \& Faccenna, C. (2002). Role of lateral thickness variations on the development of oblique structures at the Western end of the south Pyrenean central unit. Tectonophysics, 350(3), 215-235. https://doi.org/10.1016/S0040-1951(02)00116-6

Steward, S. A. (1996). Influence of detachment layer thickness on style of thin-skinned shortening. Journal of Structural Geology, 18(10), 1271-1274. https://doi.org/10.1016/S0191-8141(96)00052-1

Stockmal, G. S., Beaumont, C., Nguyen, M., \& Lee, B. (2007). Mechanics of thin-skinned fold-and-thrust belts: Insights from numerical models. In J. W. Sears (Ed.), Whence the Mountains? Inquiries into the Evolution of Orogenic Systems: A volume in Honor of Raymond A. Price, Geological Society of America Special Paper, (Vol. 433, pp. 63-98). Boulder, CO.

Storti, F., \& McClay, K. (1995). Influence of syntectonic sedimentation on thrust wedges in analogue models. Geology, 23(11), 999-1002. https://doi.org/10.1130/0091-7613(1995)023<0999:IOSSOT>2.3.CO;2

Storti, F., Salvini, F., \& McClay, K. (2000). Synchronous and velocity-partitioned thrusting and thrust polarity reversal in experimentally produced, doubly-vergent thrust wedges: Implications for natural orogens. Tectonics, 19(2), 378-396. https://doi.org/10.1029/ 1998TC001079

Tang, L., Yu, Y., Jia, C., Jin, Z. (2007). Differential Deformed Salt-Related Tectonics of the Kuqa Foreland Fold-Thrust Belt, Tarim Basin Northwest China. Paper presented at AAPG Annual Convention, Long Beach, California.

Vergés, J., Muñoz, J. A., \& Martínez, A. (1992). South Pyrenean fold and thrust belt: The role of foreland evaporitic levels in thrust geometry. In K. McClay (Ed.), Thrust Tectonics, (pp. 255-264). London: Chapman and Hall. https://doi.org/10.1007/978-94-011-3066-0_23

Vergés, J., Saura, E., Casciello, E., \& Fernàndez, M. (2011). Crustal-scale cross-sections across the NW Zagros belt: Implications for the Arabian margin reconstruction. Geological Magazine, 148(5-6), 739-761. https://doi.org/10.1017/S0016756811000331

Verschuren, M., Nieuwland, D., \& Gast, J. (1996). Multiple detachment levels in thrust tectonics: Sandbox experiments and palinspastic reconstruction. In P. G. Buchanan, \& D. A. Nieuwland (Eds.), Modern developments in structural interpretation, validation and modelling, (pp. 227-234). London: Geological Society, Special Publications.

Wang, C., Chen, H., Cheng, X., \& Li, K. (2013). Evaluating the role of syn-thrusting sedimentation and interaction with frictional detachment in the structural evolution of the SW Tarim basin, NW China: Insights from analogue modeling. Tectonophysics, 608, 642-652. https://doi.org/10.1016/j.tecto.2013.08.016

Wang, W., Yin, H., Jia, D., \& Li, C. (2017). A sub-salt structural model of the Kelasu structure in the Kuqa foreland basin, Northwest China. Marine and Petroleum Geology, 88, 115-126. https://doi.org/10.1016/j.marpetgeo.2017.08.008

Wang, X., Suppe, J., Guan, S., Hubert-Ferrari, A., Gonzalez-Mieres, R., \& Jia, C. (2011). Cenozoic structure and tectonic evolution of the Kuqa fold belt, southern Tianshan, China. In K. McClay, J. Shaw, \& J. Suppe (Eds.), Thrust Fault-Related Folding, AAPG Memoir, (Vol. 94, pp. 215-243). Tulsa, OK.

Willett, S. D. (1999). Orogeny and orography: The effects of erosion on the structure of mountain belts. Journal of Geophysical Research, 104(B12), 28,957-28,981. https://doi.org/10.1029/1999JB900248

Wu, J. E., \& McClay, K. R. (2011). Two-dimensional analog modeling of fold and thrust belts: Dynamic interactions with syncontractional sedimentation and erosion. In K. McClay, J. Shaw, \& J. Suppe (Eds.), Thrust Fault-Related Folding, AAPG Memoir, (Vol. 94, pp. 301-333). Tulsa, OK.

Wu, Z., Yin, H., Wang, X., Zhao, B., \& Jia, D. (2014). Characteristics and deformation mechanism of salt-related structures in the western Kuqa depression, Tarim basin: Insights from scaled sandbox modeling. Tectonophysics, 612-613, 81-96. https://doi.org/10.1016/j. tecto.2013.11.040

$\mathrm{Xu}, \mathrm{C} .$, \& Zhou, X. (2007). Seismic interpretation of the Kelasu triangle zone in the southern Tian Shan foothills, northwestern China. American Association of Petroleum Geologists Bulletin, 91(2), 161-171. https://doi.org/10.1306/09070606077

Yin, A., Nie, S., Craig, P., Harrison, T. M., Ryerson, F. J., Xianglin, Q., \& Geng, Y. (1998). Late Cenozoic tectonic evolution of the southern Chinese Tian Shan. Tectonics, 17(1), 1-27. https://doi.org/10.1029/97TC03140

Zhang, Z., Shen, Z., Sun, J., Wang, X., Tian, Z., Pan, X., \& Shi, L. (2015). Magnetostratigraphy of the Kelasu section in the Baicheng depression, southern Tian Shan, northwestern China. Journal of Asian Earth Sciences, 111, 492-504. https://doi.org/10.1016/j. jseaes.2015.06.016

Zhang, Z., Sun, J., Tian, Z., \& Gong, Z. (2016). Magnetostratigraphy of syntectonic growth strata and implications for the late Cenozoic deformation in the Baicheng depression, southern Tian Shan. Journal of Asian Earth Sciences, 118, 111-124. https://doi.org/10.1016/j. jseaes.2015.12.024

Zhao, W., Zhang, S., Wang, F., Cramer, B., Chen, J., Sun, Y., et al. (2005). Gas systems in the Kuche depression of the Tarim Basin: Source rock distributions, generation kinetics and gas accumulation history. Organic Geochemistry, 36(12), 1583-1601. https://doi.org/10.1016/ j.orggeochem.2005.08.016 